University of Nebraska - Lincoln

DigitalCommons@University of Nebraska - Lincoln

Faculty Publications: Department of

Entomology

Entomology, Department of

2017

\title{
Evaluation of SmartStax and SmartStax PRO Maize against Western Corn Rootworm and Northern Corn Rootworm: Efficacy and Resistance Management
}

\author{
Graham P. Head \\ Monsanto LLC, St. Louis, MO \\ Matthew W. Carroll \\ Monsanto LLC, St. Louis, MO, matthew.carroll@monsanto.com \\ Sean P. Evans \\ Monsanto LLC, St. Louis, MO \\ Dwain M. Rule \\ Dow AgroSciences LLC, Indianapolis, IN
}

Alan R. Willse

Monsanto LLC, St. Louis, MO

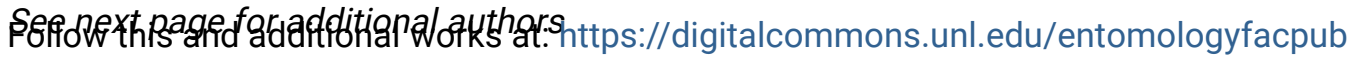 \\ Part of the Agriculture Commons, Ecology and Evolutionary Biology Commons, Entomology \\ Commons, and the Genetics and Genomics Commons}

Head, Graham P.; Carroll, Matthew W.; Evans, Sean P.; Rule, Dwain M.; Willse, Alan R.; Clark, Thomas L.; Storer, Nicholas P.; Flannagan, Ronald D.; Samuel, Luke W.; and Meinke, Lance, "Evaluation of SmartStax and SmartStax PRO Maize against Western Corn Rootworm and Northern Corn Rootworm: Efficacy and Resistance Management" (2017). Faculty Publications: Department of Entomology. 682.

https://digitalcommons.unl.edu/entomologyfacpub/682

This Article is brought to you for free and open access by the Entomology, Department of at DigitalCommons@University of Nebraska - Lincoln. It has been accepted for inclusion in Faculty Publications: Department of Entomology by an authorized administrator of DigitalCommons@University of Nebraska - Lincoln. 


\section{Authors}

Graham P. Head, Matthew W. Carroll, Sean P. Evans, Dwain M. Rule, Alan R. Willse, Thomas L. Clark, Nicholas P. Storer, Ronald D. Flannagan, Luke W. Samuel, and Lance Meinke 


\title{
Evaluation of SmartStax and SmartStax PRO Maize against Western Corn Rootworm and Northern Corn Rootworm: Efficacy and Resistance Management
}

\author{
Graham P. Head, ${ }^{1}$ Matthew W. Carroll, ${ }^{1}$ Sean P. Evans, ${ }^{1}$ \\ Dwain M. Rule, ${ }^{2}$ Alan R. Willse, ${ }^{1}$ Thomas L. Clark, ${ }^{1}$ \\ Nicholas P. Storer, ${ }^{2}$ Ronald D. Flannagan, ${ }^{1}$ \\ Luke W. Samuel, ${ }^{1}$ and Lance J. Meinke ${ }^{3}$
}

1 Monsanto LLC, St. Louis, MO, USA

2 Dow AgroSciences LLC, Indianapolis, IN, USA

3 Department of Entomology, University of Nebraska-Lincoln, Lincoln, NE, USA

Corresponding author - M. Carroll, Monsanto LLC, 800 North Lindbergh Blvd, St. Louis, MO 63167, USA.email matthew.carroll@monsanto.com

\begin{abstract}
Background: Cases of western corn rootworm (WCR) field-evolved resistance to Cry3Bb1 and other corn rootworm (CRW) control traits have been reported. Pyramid products expressing multiple CRW traits can delay resistance compared to single trait products. We used field studies to assess the pyramid CRW corn products, SmartStax (expressing Cry3Bb1 and Cry34Ab1/Cry35Ab1) and SmartStax PRO (expressing Cry3Bb1, Cry34Ab1/Cry35Ab1 and DvSnf7), at locations with high WCR densities and possible Cry3Bb1 resistance, and to assess the reduction in adult emergence attributable to DvSnf7 and other traits. Insect resistance models were used to assess durability of SmartStax and SmartStax PRO to WCR resistance.

Results: SmartStax significantly reduced root injury compared to non-CRW-trait controls at all but one location with measurable WCR pressure, while SmartStax PRO significantly reduced root injury at all locations, despite evidence of Cry3Bb1 resistance at some locations. The advantage of SmartStax PRO over SmartStax in reducing root damage was positively correlated with root damage on nonCRW-trait controls. DvSnf7 was estimated to reduce WCR emergence by approximately $80-95 \%$, which modeling indicated will improve durability of Cry3Bb1 and Cry34Ab1/Cry35Ab1 compared to SmartStax.
\end{abstract}

Conclusion: The addition of DvSnf7 in SmartStax PRO can reduce root damage under high WCR densities and prolong Cry3Bb1 and Cry34Ab1/Cry35Ab1 durability.

Keywords: insect resistance management, corn rootworm, pyramids, RNA, DvSnf7 


\section{Introduction}

Maize (Zea mays L.) hybrids producing insecticidal proteins derived from $\mathrm{Ba}$ cillus thuringiensis $(B t)$ and targeting the corn rootworm (CRW) pest complex (Diabrotica spp.) were first introduced in the US Corn Belt in 2003 with the commercialization of MON863 (Cry3Bb1, from Bt subsp. kumamotoensis) by Monsanto Company. This was followed in 2006 by the release of DAS-59122-7 by Dow AgroSciences, which expresses the binary Cry34Ab1/ Cry35Ab1 proteins from Bt strain PS149B1. At the time these products were released, each one individually was shown to provide consistent protection against $C R W^{1-4}$ though neither product is considered high dose (25 times the $B t$ concentration necessary to kill susceptible larvae ${ }^{5}$ ). In 2007, MON863 was replaced by another event expressing Cry3Bb1, MON88017. In 2009, Monsanto Company and Dow AgroSciences collaboratively registered the combined product MON89034 × TC1507 × MON88017 × DAS-59122-7, a pyramid product targeting key lepidopteran and coleopteran pests. Commercially released as SmartStax ${ }^{\circledR}$, MON89034 $\times$ TC1507 $\times$ MON88017 $\times$ DAS-59122-7 produces three $B t$ proteins that protect against lepidopteran feeding damage: Cry1A.105 (a modified Cry1A Bt protein), Cry2Ab2 (from Bt subsp. kurstaki), and Cry1F (from Bt var. aizawai); as well as three Bt proteins (two modes of action) that protect against CRW (Cry3Bb1 and Cry34Ab1/ Cry35Ab1). SmartStax was the first product with multiple traits targeting the Diabrotica spp. complex and is more effective against CRW, especially western corn rootworm (WCR; Diabrotica virgifera virgifera LeConte) and northern corn rootworm (NCR; Diabrotica barberi Smith \& Lawrence), than products containing the single events MON88017 or DAS-59122-7.3,4 Each of the Bt proteins in SmartStax reduces adult WCR emergence by about $95 \%$ and, when combined, reduce adult emergence by $99 \% .{ }^{4}$ Given the absence of cross-resistance between Cry3Bb1 and Cry34Ab1/35Ab1, ${ }^{6-9}$ such a pyramid can be predicted to prolong the durability of the individual proteins to WCR resistance, although the improvement in durability depends on whether resistance has already developed to single-trait products.

More recently, Monsanto and Dow AgroSciences have collaborated on another combined-trait product, MON89034 × TC1507 × MON87411 $\times$ DAS-59122-7, which includes a novel dsRNA mode of action targeting CRW developed by Monsanto Company. This new product is currently under consideration for registration by the US EPA and pending approval will be made commercially available as SmartStax PRO ${ }^{\circledR}$. SmartStax PRO contains the same lepidopteran control components as SmartStax but has additional insect resistance management (IRM) value against CRW because of the addition of a third trait targeting the Diabrotica spp. complex. The new event MON87411 contains Cry3Bb1, which has a similar expression profile to Cry3Bb1 in MON 88017 and SmartStax, and DvSnf7 (DvSnf7 - Diabrotica 
virgifera (Dv) + sucrose-non-fermenting (SNF) locus), a novel RNAi-based trait which targets a specific RNA sequence of WCR. The latter results in the formation of a dsRNA transcript containing a 240-bp fragment of the WCR Snf7 gene. Upon consumption, the plant-produced dsRNA in MON 87411 is specifically recognized by the RNA interference (RNAi) machinery of WCR and other closely related CRW species, resulting in down-regulation of the targeted DvSnf7 gene and leading to mortality. ${ }^{10,11}$ However, mortality of WCR occurs at a slower rate than for $B t$ proteins, beginning approximately five days after ingestion of the dsRNA. ${ }^{10}$

Of the CRW species targeted by the pyramid products containing the events MON88017, DAS-59122-7, and MON87411, WCR and NCR are the most prevalent and significant economic coleopteran pests of maize in the US Corn Belt. ${ }^{12-14}$ In 2011, cases of field-evolved resistance in WCR to Cry3Bb1 were reported for populations collected from 2009 grower fields in lowa. ${ }^{6,9}$ Since then, additional cases of field-evolved WCR resistance to Cry3Bb1, and cross-resistance between Cry3Bb1 and mCry3A, have been reported. ${ }^{7,15}$ More recently, resistance to Cry34Ab1/Cry35Ab1 has been reported in several field-collected populations of WCR. ${ }^{9}$ Once resistance has evolved to one or more of the single traits in a pyramid product, resistance to the overall pyramid product will occur more quickly. However, data show that there is no cross-resistance between Cry3Bb1 and Cry34Ab1/35Ab16 and recent studies have demonstrated a lack of cross-resistance between DvSnf7 and Cry3Bb1. ${ }^{16}$ Because there are only four commercially available traits targeting CRW (Cry3Bb1, Cry34Ab1/Cry35Ab1, mCry3A, and eCry3.1Ab), and only one novel trait (DvSnf7) is expected to be released in the next five years, understanding how current and future pyramid products perform under field-relevant conditions is important to product stewardship, grower use of the product, and development of management recommendations.

Here we present the results of three years of adult CRW emergence and root damage rating (RDR) trials conducted by Monsanto and Dow AgroSciences on naturally infested grower maize fields selected to challenge CRW products. The objectives are 1) to evaluate the performance of SmartStax and SmartStax PRO in preventing root injury; 2) to estimate the reduction in adult beetle emergence attributable to SmartStax, SmartStax PRO, and their constituent traits, in particular DvSnf7; and 3) to compare the durability of SmartStax and SmartStax PRO with 5\% seed blend refuge under a variety of assumptions about existing Cry3Bb1 and Cry34Ab1/Cry35Ab1 resistance levels.

Because WCR is more widely distributed than NCR, is a more economically important maize pest, and has a history of evolving resistance to several common chemical insecticides, the focus of this paper is on WCR, although NCR data were also collected and are reported where available. 


\section{Materials and methods}

Field trials were independently conducted by Monsanto and Dow AgroSciences to evaluate the effectiveness of CRW protected maize hybrids containing the coleopteran-active traits Cry3Bb1, DvSnf7 dsRNA, and Cry34Ab1/ Cry35Ab1. Efficacy was evaluated through small-plot root injury evaluations using the lowa State University $0-3$ nodal injury scale ${ }^{17}$ (NIS; section 2.1) and tented cages to estimate adult CRW beetle emergence (section 2.2) compared to control treatments. Because adult emergence can occur over a prolonged period, adult emergence and root injury evaluations were conducted on separate sets of maize plants that were in close proximity in the same fields. The lepidopteran-active traits of SmartStax and SmartStax PRO (Cry1A.105, Cry2Ab2, and Cry1F) were not evaluated in this study and are not discussed further. Control treatments in all trials consisted of genetic isoline hybrids without traits (Bt or DvSnf7) that target CRW (hereafter referred to as the non-CRW-trait control).

\subsection{Evaluation of CRW feeding injury}

\subsubsection{Plant materials}

From 2013 to 2015, field trials evaluating the ability of plant-incorporated protectants to protect maize root systems from CRW larval feeding were conducted by Monsanto and Dow AgroSciences in fields naturally infested with WCR and NCR. Independent studies were carried out by each company using similar methods. Protocols were generally aligned between companies but some different treatments were included (Table 1).

Table 1. Materials planted by Monsanto and Dow AgroSciences in 2013-2015 studies evaluating CRW larval root injury and adult beetle emergence.

\begin{tabular}{|c|c|c|c|c|}
\hline $\begin{array}{l}\text { Commercial name } \\
\text { (abbreviation) }\end{array}$ & CRW control trait & Events $^{a}$ & Treatment & Year \\
\hline Control & Control (no CRW trait) & NA & $100 \%$ Non-CRW & $2013^{b}, c, 2014^{b}, c, 2015^{b}, c$ \\
\hline VT Triple PRO (VT3P) & Cry3Bb1 & MON89034 × MON88017 & 100\% Traited & $2013^{b}, 2014^{b}, c, 2015^{c}$ \\
\hline Herculex RW (HXRW) & Cry34Ab1/Cry35Ab1 & DAS-59122-7 & 100\% Traited & $2013^{b}, 2014^{b}, c, 2015^{c}$ \\
\hline MON87411 & Cry3Bb1 + DvSnf7 RNAi & MON87411 & $100 \%$ Traited & $2013^{b}, c, 2014^{b}, c, 2015^{b}, c$ \\
\hline SmartStax (SS) & $\begin{array}{l}\text { Cry3Bb1 + } \\
\text { Cry34Ab1/Cry35Ab1 }\end{array}$ & $\begin{array}{l}\text { MON89034 } \times \text { TC1507 } \times \\
\text { MON88017 } \times \text { DAS-59122-7 }\end{array}$ & 100\% Traited & $2013^{b}, c, 2014^{b}, c, 2015^{c}$ \\
\hline SmartStax PRO (SSP) & $\begin{array}{l}\text { Cry3Bb1 + DvSnf7 RNAi } \\
\quad \times \text { Cry34Ab1/Cry35Ab1 }\end{array}$ & $\begin{array}{l}\text { MON89034 } \times \text { MON87411 } \\
\times \text { DAS-59122-7 }\end{array}$ & 100\% Traited & $2013^{b}, c, 2014^{b}, c, 2015^{b}, c$ \\
\hline
\end{tabular}

a. Events in bold type contain CRW resistance genes

b. Monsanto locations

c. Dow AgroSciences locations 


\subsubsection{Study locations}

RDR studies were conducted throughout the Corn Belt in areas where CRW infestation is common. During the three years of the study, 56 individual RDR studies were planted across 10 states (data not shown). However, full evaluations were only made at 44 locations where CRW were observed (Table 2).

Based on field history, study locations were expected to provide a high infestation level of CRW, and in many cases, were suspected of having WCR with some level of resistance to one or more commercially available Bt products. Specifically, maize fields were chosen to meet one or more of the following criteria: 1) investigated for Cry3Bb1 performance issues due to greater than expected damage (GTED) by CRW larvae during the previous growing season (NIS>1 for VT Triple PRO ${ }^{\circledR}$; NIS > 0.75 for SmartStax); 2) suspected of having high WCR densities in reasonable proximity to fields meeting criterion 1; and/or 3) planted to a product containing a CRW trait other than Cry3Bb1, but suspected of having GTED from CRW. In addition, some locations were also developed as trap-crops and managed to attract WCR during the previous growing season (Table 2).

\subsubsection{Planting and experimental design}

Field studies were established in accordance with local recommendations for high yield levels. As such, agronomic variables including tillage, herbicide program, and timing and rate of soil amendments varied across research locations. Treatments were arranged using a randomized complete block design and replicated four or six times at each location. Plots consisted of a single row between 3 and $3.8 \mathrm{~m}$ in length at $76.2-\mathrm{cm}$ row spacing and within-row plant spacing of 14 to $18 \mathrm{~cm}$. To minimize any potential effects of adjacent treatments on one another, buffer plots of either a nearisoline SmartStax hybrid or isoline non-CRW-trait hybrid were placed between experimental treatments.

\subsubsection{Root injury evaluations}

Root evaluations occurred after maximum larval feeding had been reached and prior to the onset of significant root regrowth. This was determined through periodic evaluations of non-CRW-trait material within the border areas of the study field. In general, treatment evaluations occurred just prior to pollination through the R2 growth stage of the crop. To assess larval feeding within the treatments, sub-samples of five or 10 representative maize plants were selected from within the interior of each plot and tagged for identification purposes. Root systems of tagged plants were manually or mechanically extracted, washed, and rated using the lowa State University 0-3 nodal injury scale. ${ }^{17}$ 
Table 2. Study sites from 2013 to 2015 evaluating root injury (RDR), adult emergence (AE) or both.

\begin{tabular}{|c|c|c|c|c|c|}
\hline Year & State & Location & Site class ${ }^{a}$ & Company & Study type \\
\hline \multirow[t]{11}{*}{2013} & Illinois & Princeton & GTED & Monsanto & RDR \\
\hline & lowa & Coon Rapids & GTED & Monsanto & RDR \\
\hline & lowa & Glidden & GTED & Monsanto & $\mathrm{RDR}^{\mathrm{b}}$ \\
\hline & Nebraska & Hordeville & GTED & Monsanto & RDR \\
\hline & Indiana & Fowler & $\mathrm{TC}$ & Dow AgroSciences & RDR \\
\hline & lowa & Clinton & $\mathrm{TC}$ & Dow AgroSciences & RDR \\
\hline & lowa & Rudd & GTED/TC & Dow AgroSciences & $\mathrm{RDR}^{\mathrm{b}}$ \\
\hline & Illinois & Lexington & $\mathrm{TC}$ & Dow AgroSciences & RDR \\
\hline & Minnesota & Peterson & GTED/TC & Dow AgroSciences & RDR \\
\hline & Minnesota & Springfield & $\mathrm{TC}$ & Dow AgroSciences & RDR \\
\hline & Wisconsin & Arlington & $\mathrm{TC}$ & Dow AgroSciences & RDR \\
\hline \multirow[t]{18}{*}{2014} & lowa & Newton & GTED & Monsanto & $A E$, RDR \\
\hline & lowa & Breda & GTED & Monsanto & $A E, R D R$ \\
\hline & lowa & Ogden & GTED & Monsanto & $A E, R D R$ \\
\hline & lowa & Willey & GTED & Monsanto & $\mathrm{AE}$ \\
\hline & Nebraska & Columbus & GTED & Monsanto & RDR \\
\hline & Nebraska & Shelby & GTED & Monsanto & RDR \\
\hline & lowa & Charles City & GTED/TC & Dow AgroSciences & $\mathrm{AE}, \mathrm{RDR}$ \\
\hline & lowa & Clinton & $\mathrm{TC}$ & Dow AgroSciences & RDR \\
\hline & lowa & Rudd & GTED/TC & Dow AgroSciences & $A E$, RDR \\
\hline & lowa & Walcott & $\mathrm{TC}$ & Dow AgroSciences & RDR \\
\hline & Illinois & Lexington & GTED/TC & Dow AgroSciences & RDR \\
\hline & Illinois & Union Hill & GTED & Dow AgroSciences & $A E$, RDR \\
\hline & Minnesota & Lanesboro & GTED/TC & Dow AgroSciences & $\mathrm{AE}, \mathrm{RDR}$ \\
\hline & Minnesota & Peterson & GTED/TC & Dow AgroSciences & RDR \\
\hline & Minnesota & Springfield & GTED/TC & Dow AgroSciences & RDR \\
\hline & Nebraska & York & $\mathrm{TC}$ & Dow AgroSciences & RDR \\
\hline & South Dakota & Colman & $\mathrm{TC}$ & Dow AgroSciences & RDR \\
\hline & Wisconsin & Arlington & $\mathrm{TC}$ & Dow AgroSciences & RDR \\
\hline \multirow[t]{18}{*}{2015} & Colorado & Stratton & GTED & Monsanto & RDR \\
\hline & lowa & Cumberland & GTED & Monsanto & $A E, R D R$ \\
\hline & lowa & Massena & GTED & Monsanto & RDR \\
\hline & lowa & Mount Auburn & GTED & Monsanto & $A E, R D R$ \\
\hline & lowa & Washington & $\mathrm{TC}$ & Monsanto & $A E, R D R$ \\
\hline & lowa & West Union & GTED & Monsanto & $A E^{b}$ \\
\hline & Kansas & Goodland & GTED & Monsanto & RDR \\
\hline & Nebraska & Beemer & GTED & Monsanto & RDR \\
\hline & Nebraska & Saunders & $\mathrm{TC}$ & Monsanto & $A E$ \\
\hline & Nebraska & West Point & GTED & Monsanto & RDR \\
\hline & Nebraska & Wood River & GTED & Monsanto & RDR \\
\hline & lowa & Rudd & GTED/TC & Dow AgroSciences & $A E$, RDR \\
\hline & lowa & Walcott & $\mathrm{TC}$ & Dow AgroSciences & $\mathrm{AE}, \mathrm{RDR}$ \\
\hline & Illinois & Lexington & GTED/TC & Dow AgroSciences & $\mathrm{AE}, \mathrm{RDR}$ \\
\hline & Indiana & Fowler & $\mathrm{TC}$ & Dow AgroSciences & RDR \\
\hline & Minnesota & Lanesboro & GTED/TC & Dow AgroSciences & $A E$, RDR \\
\hline & Minnesota & Peterson & GTED/TC & Dow AgroSciences & RDR \\
\hline & Wisconsin & Arlington & GTED/TC & Dow AgroSciences & RDR \\
\hline
\end{tabular}

a. GTED refers to locations with documented or suspected greater-than-expected damage performance issues; TC refers to developed trap-crop locations.

b. Adult emergence data not included due to agronomic issues. 


\subsection{CRW beetle emergence}

\subsection{Plant materials}

In 2014 and 2015, Monsanto and Dow AgroSciences initiated independent studies with similar treatment combinations under an aligned protocol (Table 1). Each study location contained a non-CRW-trait control and individual traits and/or combinations of traits found in SmartStax PRO. At Monsanto locations, the identity of all plants was verified using SmartStax lateral-flow membrane strips (AS-087-LS, Envirologix, Portland, ME, USA) while treatments with DvSnf7 dsRNA were assessed by endpoint TaqMan ${ }^{\circledR}$ PCR of the leaf tissue that categorized the results as positive, negative, or not callable. Dow AgroSciences used a combination of lateral-flow membrane strips and glyphosate and glufosinate selection sprays to verify presence/absence of CRW traits.

\subsubsection{Study locations}

Monsanto and Dow AgroSciences each independently established adult CRW emergence studies on fields naturally infested with WCR and NCR that were expected to have heavy CRW pressure and were suspected to include WCR with some level of resistance to Cry3Bb1. These fields met one or more of the criteria described in section 2.1.2. In addition, some fields were also developed trap-crop locations planted to hosts attractive to WCR. Emergence studies were conducted in states with persistent CRW populations in diverse corn management systems. Most trials occurred in lowa but trials were also placed in Illinois, Minnesota, and Nebraska (Table 2).

\subsubsection{Planting and experimental design}

Experimental units consisted of four rows $3.65 \mathrm{~m}$ in length at $76.2-\mathrm{cm}$ row spacing and $15.24-\mathrm{cm}$ plant spacing. In 2014, the targeted plant population at Monsanto locations was 10 plants per row for a total of 40 plants per plot, and 20 plants per row for a total of 80 plants per plot at Dow AgroSciences study locations. In 2015, the targeted plant population for both companies was 20 plants per row for a total of 80 plants per plot. Target populations were achieved by overplanting and thinning to the desired plant stand. Individual plots were separated by fallow ground to prevent larval movement between treatments. Treatments in 2014 and 2015 were planted in a randomized complete block design and replicated three times at Monsanto study locations and four times at Dow AgroSciences locations.

2.2.4 Northern corn rootworm and western corn rootworm adult emergence In 2014 and 2015, beetle emergence was determined by placing cages ( $3.7 \mathrm{~m}$ $\times 3.7 \mathrm{~m} \times 1.9 \mathrm{~m}$ high) over the four-row plots to contain emerging CRW adults. Newly emerged beetles were collected approximately twice weekly 
and stored frozen (Monsanto) or in a solution of 70\% alcohol (Dow AgroSciences) until processed. Collections were made at least weekly and continued until emerging individuals were not detected for several collection periods. Upon evaluation, beetles were enumerated by species and gender. However, in 2014, a significant weather event on 31 August damaged tents at the lowa locations near Breda, Newton, Ogden and Willey. Tents were repaired within a week at Newton and Ogden, but tents could not be repaired at Breda and Willey, resulting in a shortened collection period of 17 July 2014 to 25 August 2014. Beetle collections at Newton and Ogden continued for approximately another month at both locations. Although emergence data at Breda and Willey were collected for only 39 days, comparisons of the counts with the full collections at the Newton and Ogden locations (70 days for Newton and 85 days for Ogden) indicated that the vast majority of emergence had already occurred by 39 days. Therefore, the results from all locations should be comparable and included in the analysis. For 2015 adult emergence, adult CRW collections began in late June to early July and continued until mid-to-late September at most Monsanto locations and until late September to mid-to-late October at Dow AgroSciences locations.

\subsection{Statistical analyses}

\subsubsection{Root injury evaluations}

RDR values were log-transformed and analyzed separately for each location and year using the linear mixed effects model, implemented using the Imer function in the 'Ime4' package in R (R statistical software, version 3.0.2):18

$$
\log \left(y_{i j}\right)=\mu+r_{i}+\tau_{j}+\varepsilon_{i j}
$$

where $y_{i j}$ is the RDR score for the $i$-th replicate of product $j, \mu$ is the overall mean, $r_{i} \sim N\left(0, \sigma_{r}^{2}\right)$ is the random effect of the $i$-th replicate, $\tau_{j}$ is the fixed effect for the $j$-th product, and $\varepsilon_{i j} \sim N\left(0, \sigma_{\varepsilon}^{2}\right)$ is the random error. Significance tests for pairwise comparisons were adjusted for multiple comparison using the approach described in Hommel. ${ }^{19}$ In Monsanto trials, the lowest recorded RDR value was 0.01 . To be consistent with Monsanto trials, and to allow for analysis of RDR values on a log scale, recorded RDR values of 0 in Dow AgroSciences trials were set to 0.01 prior to analysis.

In addition, an across-location-year analysis was conducted separately for Monsanto and Dow AgroSciences trials using the linear mixed-effects model:

$$
\log \left(y_{i j k}\right)=\mu+s_{k}+r_{i k}+\tau_{j}+(s \tau)_{j k}+\varepsilon_{i j k}
$$

where $y_{i j k}$ is the RDR score for the $i$-th replicate of product $j$ at location $k$, $\mu$ is the overall mean, $s_{k} \sim N\left(0, \sigma_{s}^{2}\right)$ is the random location-year effect, $r_{i k} \sim$ $N\left(0, \sigma_{r}^{2}\right)$ is the random effect of the $i$-th replicate within the $k$-th locationyear, $\tau_{j}$ is the fixed effect for the $j$-th product, $(s \tau)_{j k} \sim N\left(0, \sigma_{s \tau}{ }^{2}\right)$ is the random 
effect of interaction between product and location-year, and $\varepsilon_{i j k} \sim N\left(0, \sigma_{\varepsilon}^{2}\right)$ is the random error.

Model 2 was fit with and without the interaction term $(s \tau)_{j k}$ and the two fitted models compared using a likelihood ratio test to assess the significance of the interaction term. Under the null hypothesis that the interaction variance term is 0 , the likelihood ratio test statistic is approximately distributed as $\chi^{2}$ with 1 degree of freedom.

\subsubsection{Adult CRW beetle emergence}

Cumulative mean adult emergence counts were log-transformed and analyzed separately by location and year using a linear mixed-effects model, implemented using the Imer function in the R package "Ime4" (R statistical software, version 3.0.2):18

$$
\log \left(y_{i j}+c\right)=\mu+r_{i}+\tau_{j}+\varepsilon_{i j}
$$

where $y_{i j}$ is the number of emerging beetles for the $i$-th replicate of product $j, \mu$ is the overall mean, $r_{i} \sim N\left(0, \sigma_{r}^{2}\right)$ is the random effect of the $i$-th replicate, $\tau_{j}$ is the fixed effect for the $j$-th product, and $\varepsilon_{i j} \sim N\left(0, \sigma_{\varepsilon}^{2}\right)$ is the random error. Estimates of relative beetle emergence on a product compared to the non-CRW-trait control were based on the linear contrast between the fixed effect for the product and non-CRW-trait control; because the analysis was conducted on log-transformed emergence counts, estimates of relative emergence were obtained by exponentiating the estimated linear contrast. Significance tests for pairwise comparisons were adjusted for multiple comparison using the approach described in Hommel. ${ }^{19}$

The value $c=0.01$ was used for all within-location analyses to account for 0 counts for some replicates (primarily for plots with SmartStax PRO treatments). An alternative approach that would account for 0 counts without the need for a constant $c$ is to use a generalized linear mixed model with Poisson or overdispersed Poisson variance function; in initial analyses with this model the estimation algorithm failed to converge for some locations, so a decision was made to perform all within-location analyses using the linear mixed-effects model 3 with $c=0.01$.

The emergence data pooled across years and companies were used to estimate relative emergence on plants expressing individual proteins and various combinations of proteins by estimating pairwise linear contrasts. For example, even though DvSnf7 was not tested on its own in emergence trials, its impact on CRW beetle emergence - specifically the expected relative emergence on DvSnf7 expressing plants compared to non-CRW-trait control plants - can be estimated by contrasting emergence on SmartStax PRO plants with emergence on SmartStax plants, and by contrasting emergence on MON 87411 plants with emergence on VT3P plants; in both cases, the products contrasted differ only in whether they contain DvSnf7. 
The statistical model underlying the estimation of trait effects is:

$$
\log \left(\bar{y}_{\cdot j k}\right)=\mu+s_{k}+\tau_{j}+\varepsilon_{j k}
$$

where $\bar{y}_{. j k}$ is the average number of emerging beetles across replicates for product $j$ at location $k, \mu$ is the overall mean, $s_{k}$ is the location-year effect, $\tau_{j}$ is the effect for the $j$-th product, and $\varepsilon_{j k}$ is the random error. Note that by averaging across replicates within a location, most locations had no zero counts. Only locations with an average of 100 beetles emerging from nonCRW-trait control plots were used to estimate trait effects; for these locations, there were no zero counts.

Because the analysis was conducted on a log-transformed scale, the contrast between any two products (e.g. between SmartStax PRO and SmartStax) was estimated as a pairwise linear contrast on the log-scale, which when back-transformed to the original scale by exponentiation is an estimate of the relative emergence between the two products. When the products differ by a single trait, this estimate can be considered an estimate of the trait effect. Pairwise contrasts between all tested products were estimated using the glht function in the R package "mutcomp," with select contrasts used to estimate effects for traits of interest, specifically: DvSnf7 (by contrasting SSP with SS, and MON 87411 with VT3P), Cry34Ab1/Cry35Ab1 (by contrasting HXRW with Control, SSP with MON87411, and SS with VT3P), Cry3Bb1 (by contrasting VT3P with Control, and SS with HXRW), SS (by contrasting SS with Control), MON87411 (by contrasting MON87411 with Control, and SSP with HXRW), DvSnf7 + Cry34Ab1/Cry35Ab1 (by contrasting SSP with VT3P), and SSP (by contrasting SSP with Control).

\subsection{Modeling the durability of SmartStax and SmartStax PRO to WCR resistance}

\subsection{Insect resistance model}

To assess the relative durability of SmartStax PRO with a $5 \%$ seed blend refuge compared to SmartStax with a $5 \%$ seed blend refuge, an insect resistance model was developed which allows for larval movement between plants and for the relative potency of traits to vary by larval stage. The landscape is assumed to consist entirely of either SmartStax PRO with a 5\% seed blend refuge or SmartStax with a $5 \%$ seed blend refuge, with no additional unstructured refuge or host crops. The insect resistance model was developed in R (R statistical software, version 3.0.2). ${ }^{18}$

It is assumed that resistance to each trait is conferred by a single di-allelic locus, and that there is no cross-resistance between Cry3Bb1, Cry34Ab1/Cry35Ab1, and DvSnf7. Because it has not been shown that larval survivorship to SmartStax is the product of survivorship to the 
individual proteins Cry3Bb1 and Cry34Ab1/Cry35Ab1, it is assumed that survivorship to SmartStax is higher than expected under multiplicative assumptions. Specifically, if:

$$
\boldsymbol{w}_{\mathrm{Cry3B}}=\left(w_{\mathrm{Cry}^{3} B^{\prime}}, w r s_{\mathrm{Cry}_{3 B}}, w r r_{\mathrm{Cry3B}}\right)^{\prime}
$$

and

$$
\boldsymbol{w}_{\text {Cry3435 }}=\left(w_{\text {Cry } 3435^{\prime}}, w r s_{\text {Cry3435, }}, w r r_{\text {Cry3435 }}\right)^{\prime}
$$

are $3 \times 1$ matrices containing relative survival rates following exposure to Cry3Bb1 and Cry34Ab1/Cry35Ab1, respectively, for homozygous susceptible (SS), heterozygous (RS), and homozygous resistant (RR) individuals, then the joint survivorship for each of the nine genotypes following exposure to the combination Cry3Bb1 + Cry34Ab1/Cry35Ab1 (SmartStax) is given by the $9 \times 1$ matrix $\left(\boldsymbol{w}_{C r y 3 B} \otimes \boldsymbol{w}_{C r y 3435}\right)^{(1-\pi 12) / 2}$ where $\otimes$ is the Kronecker product, and $\pi \in[0,1]$, where $\pi_{12}=0$ implies multiplicative survival and $\pi_{12}=1$ implies that survivorship to Cry3Bb1+Cry34Ab1/Cry35Ab1 is the geometric mean of survivorship to the individual proteins. In subsequent modeling it is assumed that $\pi_{12}=1 / 2$, which, assuming $w_{S s_{C r y 3 B}}=0.05$ and wss $_{\text {Cry34/35 }}=0.05$, implies that survivorship of double homozygous susceptible individuals to SmartStax is $(0.05 \cdot 0.05)^{(1-1 / 4)}=0.011$, which is greater than the expected 0.0025 survivorship under multiplicative assumptions. Multiplicative survival is assumed between the combined traits (Cry3Bb1 + Cry34Ab1/Cry35Ab1) and DvSnf7 $\left(\pi_{(12) 3}=0\right)$.

Each model run projects resistance allele frequencies for each trait as a function of insect generation for discrete, nonoverlapping generations. Joint genotype frequencies are successively updated at each discrete insect generation based on genotype-specific survival probabilities, assuming randommating among survivors. Resistance allele frequencies for individual loci are computed by taking appropriate sums across joint genotype frequencies.

To allow for larval movement between plants, and to allow relative potency of traits to vary by larval stage, the overall survival probability or fitness of susceptible, heterozygous, and resistant insects (denoted WSS, WRS, and WRR, respectively, in Table 3 ) for a given trait $t$ is partitioned into stage-specific survival probabilities based on fitness weights $\alpha_{t 1}, \alpha_{t 2^{\prime}}$ $\ldots, \alpha_{t M}$ for M larval stages, with $\alpha_{t 1}+\alpha_{t 2}+\ldots+\alpha_{t M}=1$. Let $\boldsymbol{w}_{t}=\left(\right.$ wss $_{t}, w_{r s_{t}}$ , $\left.w r r_{t}\right)^{\prime}$ be a $3 \times 1$ matrix containing relative survival rates following exposure to trait $t$ for homozygous susceptible (SS), heterozygous (RS), and homozygous resistant (RR) individuals. The corresponding fitness at larval stage $i$ is $\boldsymbol{w}_{t}^{\text {ait }}$; note that $\boldsymbol{\Pi}_{i} \boldsymbol{w}_{t}^{\text {ait }}=\boldsymbol{w}_{t^{\prime}}$ the overall fitness, where multiplications are performed elementwise. Thus, fitness is partitioned across larval stages so that an individual exposed to trait $t$ across all larval stages will have realized fitness $\boldsymbol{w}_{t}$. 
The $27 \times 1$ matrix $\boldsymbol{s}_{i}=\left(\boldsymbol{w}_{\text {Cry3B }}^{\alpha i 1} \otimes \boldsymbol{w}_{\text {Cry3435 }}^{\alpha i 2}\right)^{(1-\pi 12) / 2} \otimes \boldsymbol{w}_{\text {DvSnf7 }}^{\alpha i 3}$ contains genotype-specific probabilities (for $3^{3}=27$ genotypes) of surviving exposure to a stack of three traits at the $i$-th larval stage. A recursive algorithm for tracking larval survivorship as a function of genotype for the general case of $T$ traits (and $T$ resistance loci) and $M$ larval stages with movement probability $\theta$ and proportion refuge $C$ can be derived by first defining the $3^{T} \times 1$ matrices:

$$
\begin{gathered}
\boldsymbol{R}(i)=\operatorname{Pr}(\text { Survive stage } i \text { on refuge plant }), i=1, \ldots, M \\
\boldsymbol{T}(i)=\operatorname{Pr}(\text { Survive stage } i \text { on traited plant) }, i=1, \ldots, M
\end{gathered}
$$

with initial values $\boldsymbol{R}(1)=1$, a $3^{T} \times 1$ matrix with all elements equal to 1 , and $\mathbf{T}(1)=\mathbf{s}_{1}$. Then for $i=2, \ldots, M, \boldsymbol{R}(i)$ and $\boldsymbol{T}(i)$ are updated by:

$$
\begin{aligned}
& \boldsymbol{R}(i)=\boldsymbol{R}(i-1) \circ \boldsymbol{P}^{i}(R \mid R)+\boldsymbol{T}(i-1) \circ \boldsymbol{P}^{i}(R \mid T) \\
& \boldsymbol{T}(i)=\boldsymbol{R}(i-1) \circ \boldsymbol{P}^{i}(T \mid R)+\boldsymbol{T}(i-1) \circ \boldsymbol{P}^{i}(T \mid T)
\end{aligned}
$$

where ${ }^{\circ}$ denotes elementwise multiplication and:

$$
\begin{aligned}
& \boldsymbol{P}_{\boldsymbol{i}}(R \mid R)=\operatorname{Pr} \text { (Survive stage } i \text { on refuge plant } \\
& \text { ( Survived stage } i-1 \text { on refuge plant ) } \\
& =[(1-\theta)+\theta C] \mathbf{1} \\
& \boldsymbol{P}_{\boldsymbol{i}}(R \mid T)=\operatorname{Pr} \text { (Survive stage } i \text { on refuge plant } \\
& \text { | Survived stage } i \text { - } 1 \text { on traited plant) } \\
& =[\theta C] 1 \\
& P_{i}(T \mid R)=\operatorname{Pr} \text { (Survive stage } i \text { on traited plant } \\
& \text { ( Survived stage } i \text { - } 1 \text { on refuge plant ) } \\
& =\theta(1-C) s_{i} \\
& \boldsymbol{P}_{\boldsymbol{i}}(T \mid T=\operatorname{Pr} \text { (Survive stage } i \text { on traited plant } \\
& \text { |survived stage } i-1 \text { on traited plant) } \\
& =(1-\theta) \boldsymbol{s}_{\boldsymbol{i}}+\theta(1-C) \boldsymbol{s}_{\boldsymbol{i}}
\end{aligned}
$$

After the M-th larval segment, the genotype-specific survival probabilities are given by $\boldsymbol{R}(M)+\boldsymbol{T}(M)$. The model was run with two rounds of movement, i.e. $M=3$ stages.

The relative potencies of Cry3Bb1 and Cry34Ab1/Cry35Ab1 are known to decrease across larval stages, ${ }^{20}$ so relative fitness weights $2 / 3,1 / 3$, and 0 are used for larval stages 1, 2, and 3, respectively. For DvSnf7, relative fitness weights are assumed to be $0.4,0.4$, and 0.2 for larval stages 1,2 , and 3 , 
respectively. For these relative fitness weights and assumed wsS $_{\text {DvSnf7 }}=0.10$, survivorship to DvSnf7 at larval stages 1,2 , and 3 are $0.10^{0.4}=0.40,0.10^{0.4}=$ $0.40,0.10^{0.2}=0.63$; the product of survival probabilities at individual larval stages is the overall survival probability or fitness value.

The stage-wise larval movement probability was assumed to be $\theta=$ 0.50 , and the overall probability of larval movement $1-(1-\theta)^{M-1}=0.75$ for $M=3$ stages. Because interplant larval movement rates at low or moderate densities are expected to be low, the level of larval movement selected here is consistent with higher movement rates that have been documented at high larval densities. ${ }^{20,21}$ Note that because the relative fitness weight for Cry3Bb1 and Cry34Ab1/Cry35Ab1 is 0 for larval stage 3, the effective total movement probability in model for SmartStax is 0.50 .

\subsubsection{Additional modeling assumptions: fitness and initial resistance allele frequencies}

It is assumed that Cry34Ab1/Cry35Ab1 and Cry3Bb1 each provide 95\% control of homozygous susceptible individuals (corresponding to fitness value WSS $=0.05$ ), and that DvSnf7 provides between $80 \%$ and $95 \%$ control of homozygous susceptible individuals, which is consistent with adult beetle emergence data presented in this paper.

Fitness values for heterozygous Cry3Bb1 resistant individuals are assumed to be either two times or 10 times that of susceptible individuals, corresponding to dominance values of 0.053 and 0.47 . Dominance values reported in the literature ${ }^{22,23}$ are closer to the upper end of the assumed values for Cry3Bb1, but those reported values are based on lower Cry3Bb1 doses from plants reared under artificial conditions and do not directly translate to plants under field conditions because in general dominance decreases as dose increases. For example, by comparing a lab-derived resistant colony with a control colony using a Cry3Bb1 dose that killed about half of the control colony, Meihls et al.22 estimated the dominance of the resistant trait to be about 0.30 . However, under field conditions, Cry3Bb1 corn kills about $95 \%$ of susceptible larvae ${ }^{20}$ so it is expected that dominance will be lower than 0.30 under such conditions.

For Cry34Ab1/Cry35Ab1, fitness values for heterozygous resistance individuals are assumed to be two times or seven times that of susceptible individuals, corresponding to dominance values of 0.053 and 0.316 . This is a conservative interpretation of Storer et al., ${ }^{24}$ who suggested that resistance to Cry34Ab1/Cry35Ab1 is almost completely or completely recessive.

Internal Monsanto data suggest that resistance to DvSnf7 is recessive, so for DvSnf7 fitness values for heterozygous resistance individuals are assumed to be two times that of susceptible individuals, corresponding to dominance values between 0.053 and 0.25 , depending on assumed wSS ${ }^{\text {DrSnf7 }}$. 
Initial resistance allele frequencies are assumed to be 0.05 or 0.50 for Cry3Bb1, and 0.01 or 0.10 for Cry34Ab1/Cry35Ab1, to reflect various field conditions across the US Corn Belt, with higher Cry3Bb1 values reflecting conditions at some of the GTED fields. Initial resistance allele frequency for DvSnf7 is assumed to be 0.005 .

A detailed list of parameter assumptions is given in Table 3.

Table 3. Parameter used in SmartStax and SmartStax PRO insect resistance models.

\begin{tabular}{lc} 
Parameter & $\begin{array}{c}\text { Values used } \\
\text { in model }\end{array}$ \\
\hline Number of generations/year & 1 \\
Seed blend refuge proportion, $C$ & 0.05 \\
Number of larval stages, $M$ & 3 \\
Stage-wise larval movement probability, $\theta$ & 0.50 \\
Total larval movement probability, $1-(1-\theta)^{M-1}$ & 0.75 \\
Non-multiplicative survival factor $\pi_{12}$ between & 0.50 \\
$\quad$ Cry3Bb1 and Cry34Ab1/Cry35Ab1 & \\
Non-multiplicative survival factor $\pi_{(12) 3}$ between & 0 \\
$\quad$ DvSnf7 and (Cry3Bb1+Cry34Ab1/Cry35Ab1) & \\
Cross-resistance & None \\
Fitness cost of resistance & None \\
Cry3Bb1: Initial resistance allele frequency & $0.05,0.50$ \\
Cry3Bb1: WSS & 0.05 \\
Cry3Bb1: WRS/WSS (relative heterozygote fitness) & 2,10 \\
Cry3Bb1: WRR & 1 \\
Cry3Bb1: Fitness weights by larval stage $\left(\alpha_{1}, \alpha_{2}^{\prime} \alpha_{3}\right)$ & $(2 / 3,1 / 3,0)$ \\
Cry34Ab1/Cry35Ab1: Initial resistance allele frequency & $0.01,0.10$ \\
Cry34Ab1/Cry35Ab1: WSS & 0.05 \\
Cry34Ab1/Cry35Ab1: WRS/WSS (relative heterozygote fitness) & 2,7 \\
Cry34Ab1/Cry35Ab1: WRR & 1 \\
Cry34Ab1/Cry35Ab1: Fitness weights by larval stage $\left(\alpha_{1}, \alpha_{2}^{\prime} \alpha_{3}\right)$ & $(2 / 3,1 / 3,0)$ \\
DvSnf7: Initial resistance allele frequency & 0.005 \\
DvSnf7: WSS & $0.05-0.20$ \\
DvSnf7: WRS/WSS (relative heterozygote fitness) & 2 \\
DvSnf7: WRR & 1 \\
DvSnf7: Fitness weights by larval stage $\left(\alpha_{1}, \alpha_{2^{\prime}} \alpha_{3}\right)$ & $(0.4,0.4,0.2)$ \\
\hline & \\
\hline & \\
& \\
&
\end{tabular}




\section{Results}

\subsection{Root injury evaluations}

The RDR of the non-CRW-trait control treatment varied substantially across Monsanto and Dow AgroSciences locations (Table 4 and Table 5). Because feeding injury is indicative of CRW pressure, mean RDR of the non-CRW-trait control was used to categorize locations based on pressure: low (mean RDR $<0.5 \mathrm{NIS}$ ), moderate (mean RDR between 0.5 and $1.0 \mathrm{NIS}$ ), or high (mean $R D R>1.0 \mathrm{NIS}$ ). Heavy feeding is a potential indicator of a resistant CRW population, therefore sites categorized as high pressure likely have populations with some degree of resistance to Cry3Bb1. Combined across locations and years, Monsanto and Dow AgroSciences conducted RDR evaluations at 44 field locations. The data from two sites in 2013, Rudd and Glidden, IA, were excluded from analyses based on agronomic conditions that are believed to have led to atypical performance of one or more treatments (data not shown). As such, only 42 locations were included in the analyses. Two locations in 2014, Columbus, NE (Table 4) and Union Hill, IL (Table 5) had

Table 4. Root damage rating by trait for 17 trials conducted byMonsanto from2013 to 2015 based on model 1 fitted separately for each location-year.

\begin{tabular}{|c|c|c|c|c|c|c|c|}
\hline Monsanto sites & $S S P^{\star}$ & SSt & HXRW & MON $87411 \S$ & VT3Pף & Control** & Pressure \\
\hline Beemer NE 2015 & $0.33^{a}$ & $1.28 \mathrm{bc}$ & $0.92^{b}$ & $1.68^{c}$ & $1.84^{c}$ & $1.69^{c}$ & High \\
\hline Newton IA 2014 & $0.06^{a}$ & $0.07^{a}$ & $0.08^{a}$ & $1.33^{b}$ & $1.72^{b}$ & $1.50^{\mathrm{b}}$ & High \\
\hline Wood River NE 2015 & $0.08^{a}$ & $0.09^{a}$ & $0.10^{a}$ & $0.08^{a}$ & $0.16^{b}$ & $1.45^{c}$ & High \\
\hline Goodland KS 2015 & $0.11^{\mathrm{a}}$ & $0.18^{a}$ & NA & $0.44^{b}$ & $0.67^{b}$ & $1.33^{c}$ & High \\
\hline Massena IA 2015 & $0.09^{a}$ & $0.17^{b}$ & $0.27^{c}$ & $0.63^{d}$ & $1.11^{\mathrm{e}}$ & $1.25^{\mathrm{e}}$ & High \\
\hline Washington IA 2015 & $0.06^{a}$ & $0.07^{a}$ & $0.13^{b}$ & $0.16^{b}$ & $0.42^{c}$ & $1.14^{d}$ & High \\
\hline Cumberland IA 2015 & $0.07^{a}$ & $0.14^{b}$ & $0.21^{b}$ & $0.22^{b}$ & $0.88^{c}$ & $1.12^{c}$ & High \\
\hline Hordeville NE 2013 & $0.05^{\mathrm{a}}$ & $0.07^{\mathrm{ab}}$ & $0.10^{\mathrm{b}}$ & $0.23^{c}$ & $0.26^{c}$ & $1.01^{d}$ & High \\
\hline Coon Rapids IA 2013 & $0.37^{a}$ & $0.38^{a}$ & $0.28^{a}$ & $0.76^{b}$ & $0.90^{b}$ & $0.89^{b}$ & Moderate \\
\hline Princeton IL 2013 & $0.07^{a}$ & $0.06^{a}$ & $0.12^{\mathrm{b}}$ & $0.26^{c}$ & $0.70^{d}$ & $0.72^{\mathrm{d}}$ & Moderate \\
\hline Breda IA 2014 & $0.04^{\mathrm{a}}$ & $0.03^{a}$ & $0.05^{\mathrm{ab}}$ & $0.08^{b}$ & $0.15^{c}$ & $0.70^{d}$ & Moderate \\
\hline West Point NE 2015 & $0.08^{a}$ & $0.10^{\mathrm{ab}}$ & $0.21^{c}$ & $0.15^{b c}$ & $0.67^{d}$ & $0.68^{d}$ & Moderate \\
\hline Stratton CO 2015 & $0.04^{a}$ & $0.07^{c}$ & $0.09 \mathrm{abc}$ & $0.08^{c}$ & $0.19^{b}$ & $0.62^{d}$ & Moderate \\
\hline Mt Auburn IA 2015 & $0.08^{a}$ & $0.10^{a}$ & $0.10^{\mathrm{ab}}$ & $0.15^{b}$ & $0.26^{c}$ & $0.54^{d}$ & Moderate \\
\hline Shelby NE 2014 & $0.05^{\mathrm{a}}$ & $0.04^{a}$ & $0.06^{a}$ & $0.06^{a}$ & $0.13^{b}$ & $0.35^{c}$ & Low \\
\hline Ogden IA 2014 & $0.03^{a}$ & $0.02^{a}$ & $0.03^{a}$ & $0.08^{b}$ & $0.06^{b}$ & $0.30^{c}$ & Low \\
\hline Columbus NE 2014 & $0.04^{a}$ & $0.04^{a}$ & $0.04^{a}$ & $0.05^{a}$ & $0.04^{a}$ & $0.06^{a}$ & Low \\
\hline
\end{tabular}

The estimates of trait effect $\tau_{j}$ in 1 correspond to log-transformed RDR values; estimates on original RDR scale shown below are given by $\exp \tau_{j}$.

Location-years are ranked by control damage rating from highest to lowest.

Letters show groupings based on pairwise tests between traits within a location-year, adjusted for multiple comparisons using Hommel's method at the 0.05 level of significance.

* SmartStax PRO (SSP)

+ SmartStax (SS); \#Herculex RW (HXRW)

$\S$ MON 874114 (Cry3Bb1+DvSnf7)

I VT Triple PRO (VT3P)

** Non-CRW-Trait Control 
Table 5. Root damage rating by trait for 25 trials conducted by Dow AgroSciences from 2013 to 2015 based on model 1 fitted separately for each location-year.

\begin{tabular}{|c|c|c|c|c|c|}
\hline Dow AgroSciences sites & $S S P^{*}$ & SSt & MON $87411 \neq$ & Controls & Pressure \\
\hline Clinton IA 2013 & $0.04^{a}$ & $0.07^{b}$ & $0.57 c$ & $2.38^{d}$ & High \\
\hline Lexington IL 2014 & $0.10^{\mathrm{a}}$ & $0.16^{\mathrm{a}}$ & $0.39^{b}$ & $2.36^{c}$ & High \\
\hline Lexington IL 2015 & $0.02^{\mathrm{a}}$ & $0.05^{b}$ & $0.72^{c}$ & $2.22^{\mathrm{d}}$ & High \\
\hline Fowler IN 2013 & $0.02^{\mathrm{a}}$ & $0.04^{b}$ & $0.06^{c}$ & $1.93^{d}$ & High \\
\hline Walcott IA 2015 & $0.02^{\mathrm{a}}$ & $0.07^{b}$ & $0.08^{b}$ & $1.72^{c}$ & High \\
\hline Charles City IA 2014 & $0.02^{\mathrm{a}}$ & $0.01^{\mathrm{a}}$ & $0.22^{\mathrm{b}}$ & $1.70^{c}$ & High \\
\hline Peterson MN 2013 & $0.02^{\mathrm{a}}$ & $0.04^{b}$ & $0.40^{c}$ & $1.55^{\mathrm{d}}$ & High \\
\hline Lanesboro MN 2015 & $0.05^{\mathrm{a}}$ & $0.14^{b}$ & $0.34^{c}$ & $1.54^{d}$ & High \\
\hline Springfield MN 2013 & $0.22^{\mathrm{a}}$ & $0.29^{b}$ & $1.12^{c}$ & $1.49^{c}$ & High \\
\hline Springfield MN 2014 & $0.04^{a}$ & $0.03^{a}$ & $0.24^{b}$ & $1.15^{c}$ & High \\
\hline Peterson MN 2015 & $0.08^{a}$ & $0.07^{a}$ & $0.45^{b}$ & $1.12^{c}$ & High \\
\hline Lanesboro MN 2014 & $0.10^{\mathrm{a}}$ & $0.31^{\mathrm{b}}$ & $0.49 \mathrm{bc}$ & $1.05^{c}$ & High \\
\hline Rudd IA 2015 & $0.01^{\mathrm{a}}$ & $0.03^{b}$ & $0.39 c$ & $1.02^{\mathrm{d}}$ & High \\
\hline York NE 2014 & $0.01^{a}$ & $0.01^{\mathrm{a}}$ & $0.01^{\mathrm{a}}$ & $0.71^{b}$ & Moderate \\
\hline Arlington WI 2013 & $0.03^{a}$ & $0.03^{a}$ & $0.07^{b}$ & $0.56^{c}$ & Moderate \\
\hline Arlington WI 2015 & $0.07^{a}$ & $0.21^{b}$ & $0.66^{c}$ & $0.48^{c}$ & Low \\
\hline Arlington WI 2014 & $0.04^{a}$ & $0.06^{b}$ & $0.06^{b}$ & $0.33^{c}$ & Low \\
\hline Walcott IA 2014 & $0.01^{\mathrm{a}}$ & $0.01^{\mathrm{a}}$ & $0.02^{b}$ & $0.27^{c}$ & Low \\
\hline Fowler IN 2015 & $0.02^{\mathrm{a}}$ & $0.04^{b}$ & $0.03^{\mathrm{ab}}$ & $0.24^{c}$ & Low \\
\hline Lexington IL 2013 & $0.03^{a}$ & $0.03^{a}$ & $0.05^{a}$ & $0.20^{\mathrm{b}}$ & Low \\
\hline Colman SD 2014 & $0.01^{a}$ & $0.03^{b}$ & $0.02^{\mathrm{ab}}$ & $0.19 c$ & Low \\
\hline Clinton IA 2014 & $0.03^{\mathrm{ab}}$ & $0.03^{a}$ & $0.05^{b c}$ & $0.07 c$ & Low \\
\hline Rudd IA 2014 & $0.01^{a}$ & $0.01^{a}$ & $0.02^{\mathrm{a}}$ & $0.05^{b}$ & Low \\
\hline Union Hill IL 2014 & $0.01^{a}$ & $0.01^{\mathrm{a}}$ & $0.01^{\mathrm{a}}$ & $0.02^{\mathrm{a}}$ & Low \\
\hline Peterson MN 2014 & $0.08^{a}$ & $0.06^{a}$ & $1.37^{\mathrm{b}}$ & NA & NA \\
\hline
\end{tabular}

The estimates of trait effect $\tau_{j}$ in 1 correspond to log-transformed RDR values; estimates on original RDR scale shown below are given by exp $\left(\tau_{j}\right)$.

Location-years are ordered by control damage rating from highest to lowest.

Letters show groupings based on pairwise tests between traits within a location-year, adjusted for multiple comparisons using Hommel's method at the 0.05 level of significance

* SmartStax PRO (SSP)

+ SmartStax (SS)

‡ MON 874114 (Cry3Bb1+DvSnf7)

$\S$ Non-CRW-Trait Control

extremely low CRW pressure, and no treatment effect could be detected. At Peterson, MN, in 2014, a non-CRW-trait control treatment was planted but not successfully established because of herbicide injury (Table 5); hence, the results of this location will be discussed only when comparing between treatments containing CRW traits. Of the remaining 39 field locations, 21 could be categorized as providing high CRW pressure (Table 4 and Table 5). While CRW pressure as measured by RDR was low at some locations, it was usually sufficient to detect differences in RDR between the non-CRWtrait control and one or more treatments with CRW traits (Table 4 and Table 5). As a complement to Table 4 and Table 5, root damage ratings by location for treatments compared to non-CRW-trait control treatments also are displayed graphically in Fig. 1 and Fig. 2 for Monsanto and Dow AgroSciences trials, respectively. 

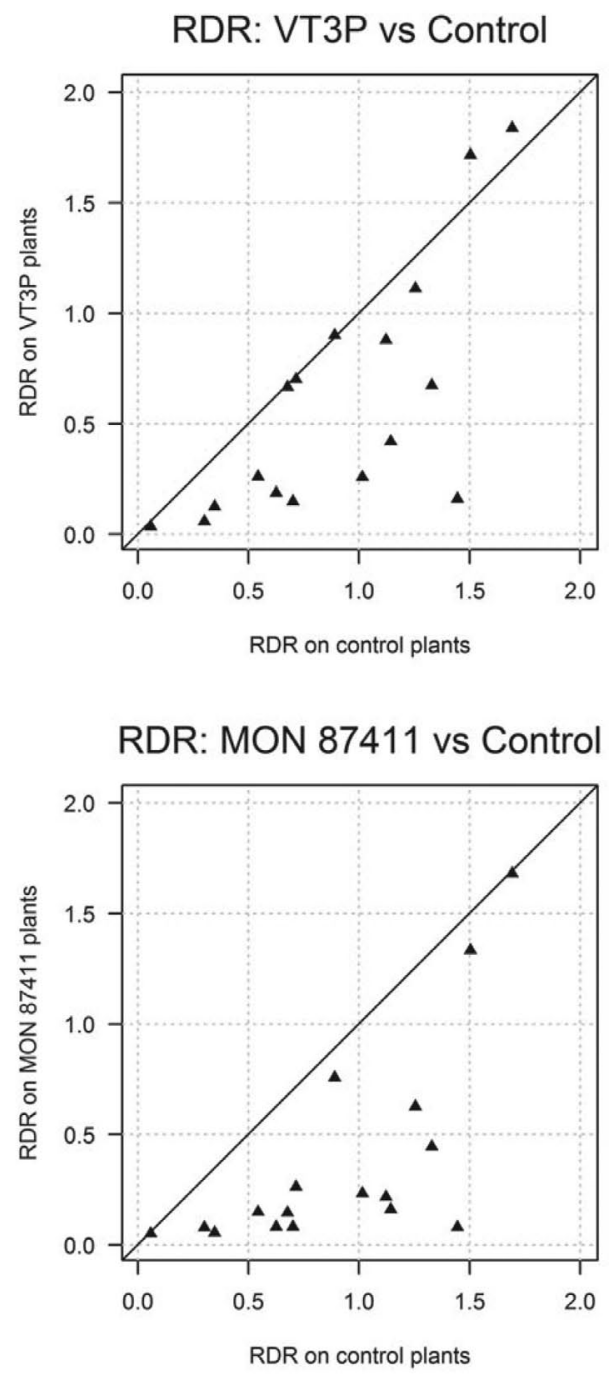
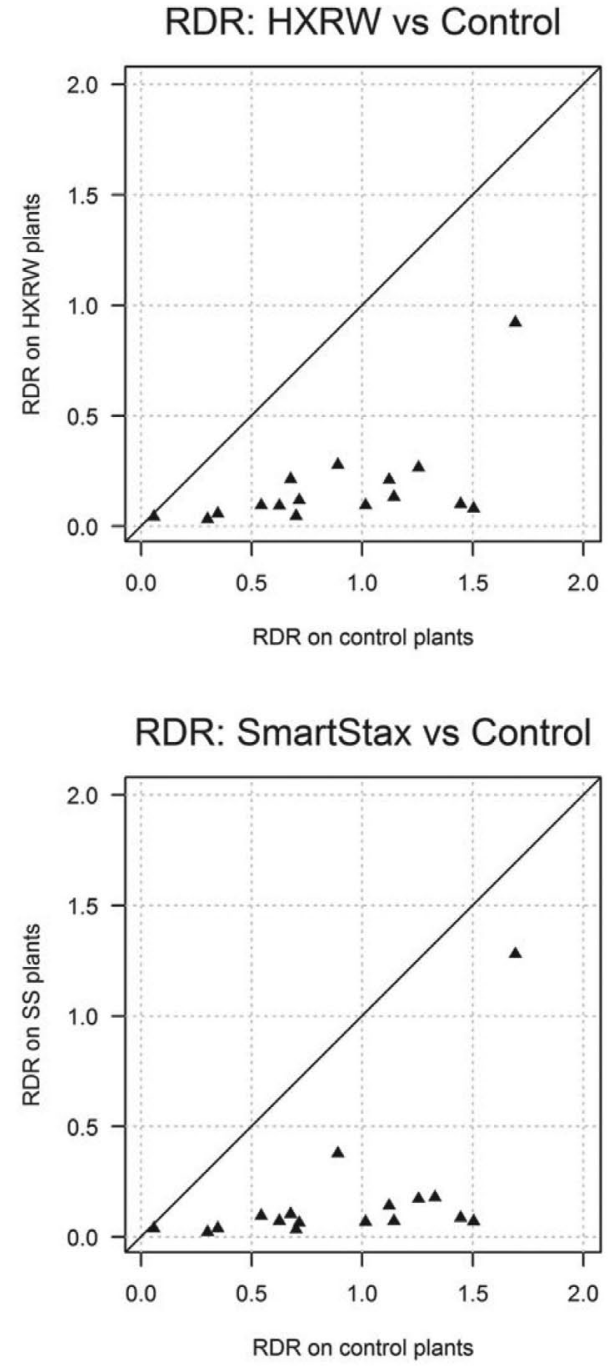

\section{RDR: SmartStax PRO vs Control}

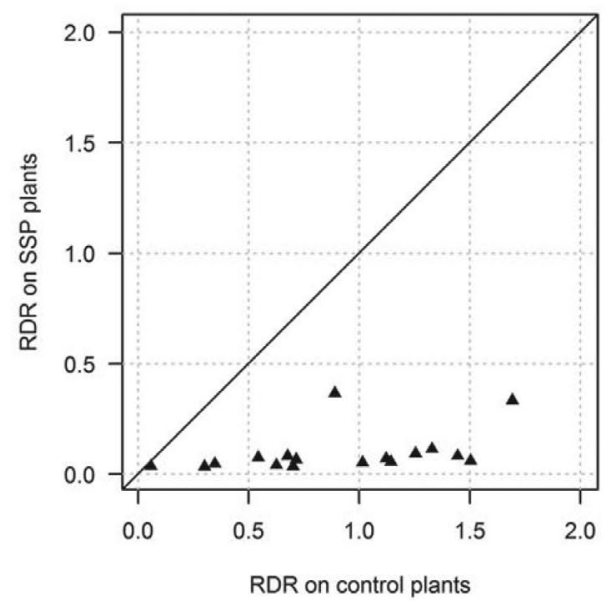

Figure 1. Root damage rating (RDR) for various products and events by locationyear for 2013-2015 Monsanto trials (Table 4). Line of equality (diagonal line) shows intersection where RDR on control plants $=$ RDR on SSP plants. 
RDR: MON 87411 vs Control

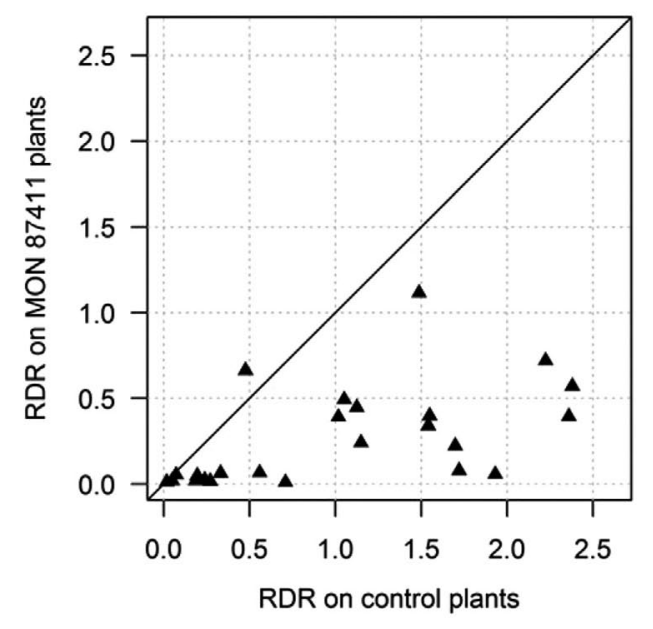

RDR: SmartStax vs Control

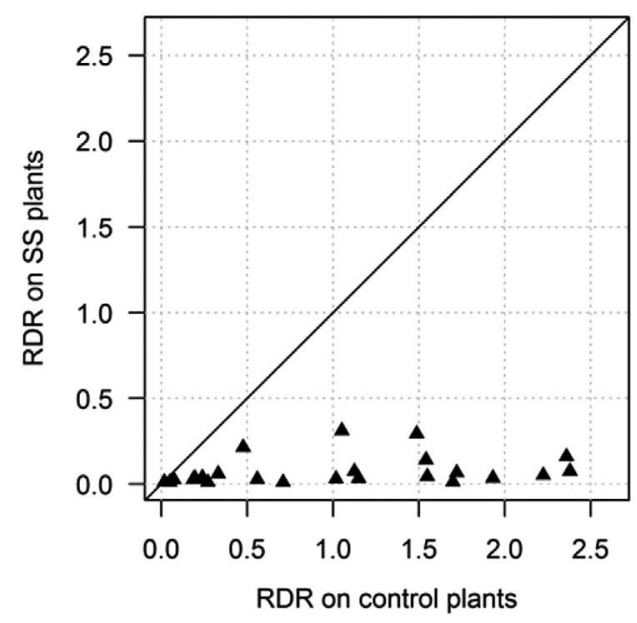

RDR: SmartStax PRO vs Control

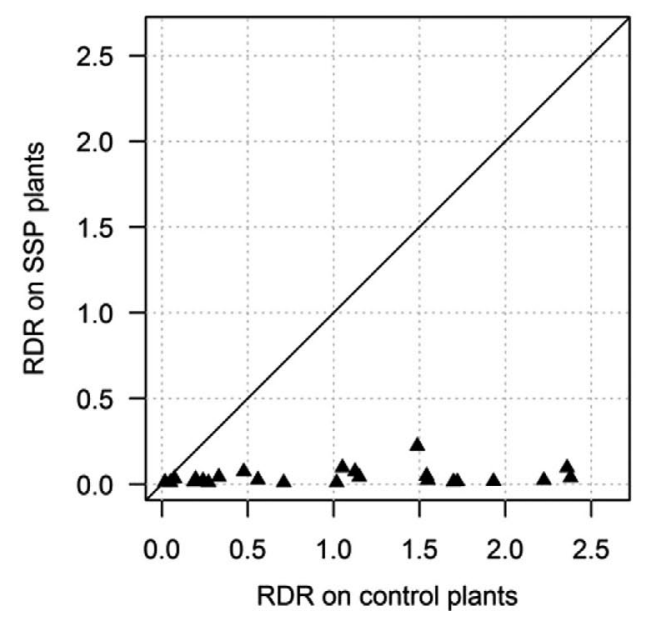

Figure 2. Root damage rating (RDR) for various products and events by locationyear for 2013-2015 Dow AgroSciences trials (Table 5). Line of equality (diagonal line) shows intersection where RDR on control plants = RDR on SSP plants.

In combined analyses across location-years using model 2, conducted separately for Monsanto and Dow AgroSciences trials, a significant interaction between location and treatment within year was detected $\left(\chi^{2}=652.3\right.$ on $1 d f, P<10^{-16}$ for MON trials; $\chi^{2}=548.5$ on $0 d f, P<10^{-16}$ for DAS trials; based on likelihood ratio comparison of model 2 with and without the interaction term), indicating that treatments performed differently across locations.

Across all trials, non-CRW-trait control treatments at 28 of 39 locations had significantly higher RDR than all other treatments (Table 4 and Table 5); exceptions occurred at seven Monsanto sites (Table 4) and four Dow 
AgroSciences sites (Table 5). At the seven Monsanto sites, the mean RDR of the non-CRW-trait controls exceeded an RDR of 1.0 NIS at four locations, with two high-CRW-pressure sites (Newton, IA, in 2014 and Beemer, NE, in 2015) having a non-CRW-trait control RDR of at least 1.5 NIS (Table 4; Fig. 1). At all seven sites, root injury for VT Triple PRO (Cry3Bb1) was similar to the non-CRW-trait controls (Table 4; Fig. 1), suggesting reduced susceptibility to Cry3Bb1 in WCR at these sites. While VT Triple PRO had statistically significant reductions in RDR at the remaining nine Monsanto sites, VT Triple PRO at the 2015 Goodland, KS, site exceeded an RDR of 0.50 NIS (Table 4; Fig. 1). In contrast, larval damage (RDR) on Herculex RW ${ }^{\circledR}$ (Cry34Ab1/ Cry35Ab1) was significantly lower than non-CRW-trait controls at all locations where these were compared (Table 4), indicating that CRW at these locations remained susceptible to Cry34Ab1/Cry35Ab1. Only one location, Beemer, NE, had an RDR for Herculex RW greater than 0.5 (Fig. 1), but the damage there was still significantly less than on the control suggesting a possible partial reduction in susceptibility to Cry34Ab1/Cry35Ab1 in this one WCR population. This location had a history of more than 15 years of continuous corn planting that included multiple years of planting of both Cry3Bb1 and Cry34Ab1/Cry35Ab1 as single trait products. Other than the described trial, it was rotated to soybeans after being investigated for CRW GTED (data not presented).

MON87411 significantly reduced mean root injury at 32 of 39 sites compared to non-CRW-trait controls (Table 4 and Table 5; Fig. 1 and Fig. 2). Of the seven sites where root injury was similar between the non-CRW-trait controls and MON87411, two were located on Monsanto fields with high CRW pressure (Newton, IA, in 2014 and Beemer, NE, in 2015) where similar levels of root injury were observed between VT Triple PRO, MON87411 and the non-CRW-trait control (Table 4; Fig. 1). In addition, at Beemer in 2015, no difference in root injury was found between the non-CRW-trait control, VT Triple PRO, MON87411 and SmartStax (Table 4). At the four Dow AgroSciences sites where root injury was similar between the non-CRW-trait controls and MON87411, RDR in the non-CRW-trait controls ranged from $<0.25$ NIS at Clinton, IA, in 2014 to 1.5 NIS at Springfield, MN, in 2013 (Table 5). At 11 of 13 Dow AgroSciences high pressure sites, MON87411 had a significantly lower RDR than the non-CRW-trait controls (Table 5; Fig 2).

Significant reductions in root injury were observed in SmartStax treatments compared to MON87411 at 26 of 40 sites. In comparison, 32 of 40 sites had significantly less damage on roots in SmartStax PRO treatments than in MON87411. In addition, less root injury was observed in SmartStax PRO than in SmartStax at 17 of 40 sites, which varied in pressure and degree of CRW resistance to Cry3Bb1. At nearly all sites, root injury in SmartStax and SmartStax PRO was low, typically much less than 0.5 NIS (Table 4 and Table 5). At only one high pressure site (Beemer, NE, in 2015) and one 


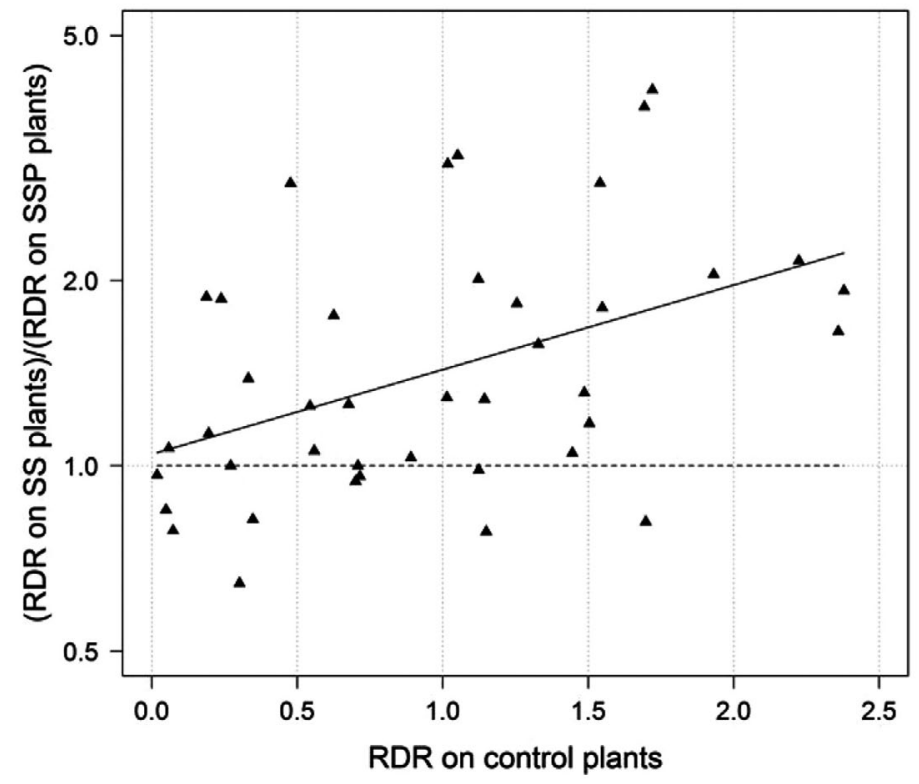

Figure 3. Relative RDR on SmartStax (SS) plants compared to SmartStax PRO (SSP) plants across all Monsanto and Dow AgroSciences trials, based on data presented in Tables 4 and 5. A linear regression on log scale, $\log (S S$ RDR/SSP RDR) = Control $\mathrm{RDR}+\varepsilon$ was fitted, showing that the log-ratio increases linearly with control RDR $F(1,39)=9.81, P=0.003, R^{2}=0.42$. On the original scale (i.e. not log-transformed), the relationship between SSP/SS ratio and control RDR is (SSP RDR/SS RDR) = $\exp (0.044+0.32 *$ Control RDR $)$.

moderate pressure site (Coon Rapids, IA, in 2013) did mean root injury scores of SmartStax PRO approach 0.5 NIS (Table 4). Nevertheless, at the 2015 Beemer location, SmartStax PRO significantly reduced root damage by at least two-fold compared to SmartStax and Herculex RW and by approximately five-fold compared with the non-CRW-trait control, VT Triple PRO and MON87411 (Table 4).

Combining data across companies, the relative advantage of SmartStax PRO over SmartStax increased with insect pressure (Fig. 3), indicating that DvSnf7 contributed to a reduction in root damage when pyramided with Bt traits, particularly under higher CRW pressure.

\subsection{Adult CRW beetle emergence}

\subsection{Western corn rootworm emergence}

Across 15 locations in 2014 and 2015 with CRW emergence studies (Tables 6-9), mean adult emergence of WCR per tent over the growing season in non-CRW-trait controls was less than 100 individuals (considered very low) at four locations in 2014 (Charles City, IA, Union Hill, IL, Breda, IA, and 
Table 6. Estimated WCR and NCR \% emergence relative to the non-CRW-trait control by CRW product for four trials conducted by Monsanto in 2014, based on model 3.

\begin{tabular}{llllllll} 
Species & Site & SSP & SSt & HXRW & MON 87411§ & VT3P & Control** $^{*}$ \\
\hline WCR & Newton IA & $0.308^{\mathrm{a}}$ & $1.49^{\mathrm{b}}$ & $1.7^{\mathrm{b}}$ & $18.5^{\mathrm{c}}$ & $108^{\mathrm{d}}$ & $1551.90^{\mathrm{d}}$ \\
WCR & Ogden IA & $1.34^{\mathrm{ab}}$ & $8.28^{\mathrm{b}}$ & $3.35^{\mathrm{ab}}$ & $0.754^{\mathrm{a}}$ & $1.83^{\mathrm{ab}}$ & $444.14^{\mathrm{c}}$ \\
WCR & Breda IA & $0.0789^{\mathrm{a}}$ & $4.29^{\mathrm{b}}$ & $4.91^{\mathrm{b}}$ & $3.9^{\mathrm{b}}$ & $180^{\mathrm{c}}$ & $59.00^{\mathrm{c}}$ \\
WCR & Willey IA & $0.0398^{\mathrm{a}}$ & $5.05^{\mathrm{b}}$ & $0.0398^{\mathrm{a}}$ & $16.6^{\mathrm{c}}$ & $115^{\mathrm{d}}$ & $25.14^{\mathrm{d}}$ \\
NCR & Newton IA & $0.207^{\mathrm{a}}$ & $0.207^{\mathrm{a}}$ & $4.49^{\mathrm{ab}}$ & $0.964^{\mathrm{a}}$ & $9.3^{\mathrm{ab}}$ & $4.83^{\mathrm{b}}$ \\
NCR & Ogden IA & $0.487^{\mathrm{a}}$ & $2.27^{\mathrm{a}}$ & $3.26^{\mathrm{a}}$ & $1.05^{\mathrm{a}}$ & $1.05^{\mathrm{a}}$ & $9.56^{\mathrm{a}}$ \\
NCR & Breda IA & $0.0205^{\mathrm{a}}$ & $0.12^{\mathrm{a}}$ & $0.804^{\mathrm{ab}}$ & $0.0205^{\mathrm{a}}$ & $18.5^{\mathrm{bc}}$ & $48.85^{\mathrm{c}}$ \\
NCR & Willey IA & $0.0209^{\mathrm{a}}$ & $0.0209^{\mathrm{a}}$ & $0.774^{\mathrm{b}}$ & $0.0209^{\mathrm{a}}$ & $0.0209^{\mathrm{a}}$ & $47.81^{\mathrm{c}}$ \\
\hline
\end{tabular}

The "Control" shows average adult emergence from the non- $B t$ treatment.

Letters show groupings based on pairwise tests between traits, adjusted for multiple comparisons using Hommel's method at the 0.05 level of significance.

* SmartStax PRO (SSP)

+ SmartStax (SS)

\# Herculex RW (HXRW)

$\S$ MON 874114 (Cry3Bb1+DvSnf7)

I VT Triple PRO (VT3P)

** Control (No CRW Trait)

Table 7. Estimated WCR and NCR \% emergence relative to the non-Bt control by trait for four trials conducted by Monsanto in 2015, based on model 3.

\begin{tabular}{lllll} 
Species & Site & SSPRO* & MON $87411+$ & Control \\
\hline WCR & Cumberland, IA & $0.226^{\mathrm{a}}$ & $2.95^{\mathrm{b}}$ & $2058.54^{\mathrm{c}}$ \\
WCR & Saunders, NE & $0.185^{\mathrm{a}}$ & $0.156^{\mathrm{a}}$ & $1476.99^{\mathrm{b}}$ \\
WCR & Washington, IA & $0.0239^{\mathrm{a}}$ & $5.29^{\mathrm{a}}$ & $1307.15^{\mathrm{b}}$ \\
WCR & Mt Auburn, IA & $0.456^{\mathrm{a}}$ & $4.05^{\mathrm{b}}$ & $765.10^{\mathrm{c}}$ \\
NCR & Cumberland IA & $0.0597^{\mathrm{a}}$ & $0.0597^{\mathrm{a}}$ & $16.74^{\mathrm{b}}$ \\
NCR & Saunders NE & $0.146^{\mathrm{a}}$ & $0.0314^{\mathrm{a}}$ & $31.87^{\mathrm{b}}$ \\
NCR & Washington IA & $0.0489^{\mathrm{ab}}$ & $2.64 b^{\mathrm{b}}$ & $443.46^{\mathrm{c}}$ \\
NCR & Mt Auburn IA & $0.126^{\mathrm{a}}$ & $0.126^{\mathrm{a}}$ & $7.95^{\mathrm{b}}$ \\
\hline
\end{tabular}

The 'Control' shows average adult emergence from the non- $B$ t treatment.

Letters show groupings based on pairwise tests between traits, adjusted for multiple comparisons using Hommel's method at the 0.05 level of significance.

*SmartStax PRO (SSP)

tMON 874114 (Cry3Bb1+DvSnf7)

¥Control (No CRW Trait)

Willey, IA) (Table 6 and Table 8). Mean WCR adult emergence from nonCRW-trait controls was moderate to high at the remaining locations in 2014 and 2015, with two locations (Lanesboro, MN, in 2014 and Cumberland, IA, in 2015) averaging approximately 2000 adults (Table 6 and Table 7) and four other locations (Newton, IA, in 2014, and Washington, IA, Saunders, NE, and Lanesboro, MN, in 2015) averaging more than 1000 adults (Tables 6-9). For context, using the planting rates for each site to estimate mean WCR on a per plant basis, the mean number of WCR emerging in the control plots 
Table 8. EstimatedWCR and NCR \% emergence relative to the non-Bt control by trait for four trials conducted by Dow AgroSciences in 2014, based on model 3.

\begin{tabular}{llllll} 
Species & Site & SSP* & SSt & MON 87411 & Controls \\
\hline WCR & Lanesboro MN & $0.247^{\mathrm{a}}$ & $2.83^{\mathrm{b}}$ & $16.5^{\mathrm{c}}$ & $2001.14^{\mathrm{d}}$ \\
WCR & Rudd IA & $2.57^{\mathrm{a}}$ & $8.35^{\mathrm{ab}}$ & $17.1^{\mathrm{b}}$ & $423.24^{\mathrm{c}}$ \\
WCR & Charles City IA & $3.17^{\mathrm{a}}$ & $7.04^{\mathrm{a}}$ & $13^{\mathrm{b}}$ & $96.04^{\mathrm{c}}$ \\
WCR & Union Hill IL & $13.8^{\mathrm{ab}}$ & $5.54^{\mathrm{a}}$ & $8.81^{\mathrm{ab}}$ & $13.61^{\mathrm{b}}$ \\
NCR & Lanesboro MN & $0.266^{\mathrm{a}}$ & $30.2^{\mathrm{c}}$ & $3.1^{\mathrm{b}}$ & $450.65^{\mathrm{d}}$ \\
NCR & Rudd IA & $0.045^{\mathrm{a}}$ & $4.49^{\mathrm{b}}$ & $0.734^{\mathrm{b}}$ & $348.77^{\mathrm{c}}$ \\
NCR & Charles City IA & $0.0128^{\mathrm{a}}$ & $0.142^{\mathrm{ab}}$ & $0.879^{\mathrm{b}}$ & $349.56^{\mathrm{c}}$ \\
NCR & Union Hill IL & $0.0543^{\mathrm{a}}$ & $0.172^{\mathrm{a}}$ & $0.0543^{\mathrm{a}}$ & $18.42^{\mathrm{b}}$ \\
\hline
\end{tabular}

The "Control" shows average adult emergence from the non- $B t$ treatment.

Letters show groupings based on pairwise tests between traits, adjusted for multiple comparisons using Hommel's method at the 0.05 level of significance.

* SmartStax PRO (SSP)

+ SmartStax (SS)

‡ MON 874114 (Cry3Bb1+DvSnf7)

$\S$ Control (No CRW Trait)

Table 9. Estimated WCR and NCR \% emergence relative to the non-CRW-trait control by trait for three trials conducted by Dow AgroSciences in 2015, based on model 3.

\begin{tabular}{|c|c|c|c|c|c|c|c|c|}
\hline Species & Site & $S S P^{*}-111+$ & $S S P^{*}$ & SS\# & HXRW§ & MON $87411 \pi$ & $V T 3 P^{* *}$ & Controltt \\
\hline WCR & Lanesboro MN & $0.0247^{a}$ & $0.0369 \mathrm{ab}$ & $0.517 \mathrm{bc}$ & $1.47^{c d}$ & $9.6^{\mathrm{de}}$ & $69.2^{\mathrm{e}}$ & $1694.37^{\mathrm{e}}$ \\
\hline WCR & Lexington IL & $0.0749^{a b}$ & $0.0127^{a}$ & $1.76^{c}$ & $1.29 \mathrm{bc}$ & $7.21^{\mathrm{cd}}$ & $98.1^{d}$ & $788.79^{d}$ \\
\hline WCR & Walcott IA & $1.28^{\mathrm{b}}$ & $0.115^{a}$ & $4.23^{b}$ & $3.92^{\mathrm{b}}$ & $7.43^{b c}$ & $71.6^{\mathrm{cd}}$ & $478.82^{d}$ \\
\hline NCR & Lanesboro MN & $0.0125^{a}$ & $0.0156^{a}$ & $6.09^{b c}$ & $13.7^{c}$ & $0.126^{\mathrm{ab}}$ & $58.4^{c}$ & $377.51^{c}$ \\
\hline NCR & Lexington IL & $0.025^{a}$ & $0.094^{\mathrm{ab}}$ & $2.66^{b c}$ & $10.8^{\mathrm{cd}}$ & $0.025^{\mathrm{a}}$ & $35.3^{\mathrm{cd}}$ & $126.95^{d}$ \\
\hline NCR & Walcott & - & - & - & - & - & - & - \\
\hline
\end{tabular}

The "Control" shows average adult emergence from the non- $B t$ treatment.

Letters show groupings based on pairwise tests between traits, adjusted for multiple comparisons using Hommel's method at the 0.05 level of significance.

* SmartStax PRO (SSP)

+ Indicates different relative maturity for this SmartStax PRO hybrid, relative maturity for all other treatments was 105 days.

‡ SmartStax (SS)

$\S$ Herculex RW (HXRW)

I MON 874114 (Cry3Bb1+DvSnf7)

** VT Triple PRO (VT3P)

++ Control (No CRW Trait)

exceeded the economic threshold for adult WCR ${ }^{25}$ of 0.5 per plant at all locations except Union Hill, IL in 2015 (Tables 6-9). In general, the combinedtrait products (SmartStax and SmartStax PRO) consistently reduced adult emergence more than single-CRW-trait products (VT Triple PRO and Herculex RW) and MON87411 (Tables 6-9).

Among seven locations that included both VT Triple PRO and Herculex RW treatments (the Monsanto locations in 2014 (Table 6) and the Dow 
AgroSciences locations in 2015 (Table 9)), mean adult WCR emergence from VT Triple PRO was similar to or exceeded that of the non-CRW-trait control at three lowa locations in 2014 (Newton, Breda, and Willey) and one location in 2015 (Lanesboro, MN). However, two of these locations, Breda and Willey, had extremely low WCR pressure and there was little variation in trait performance. In comparison, mean WCR adult emergence from Herculex RW was significantly lower than the non-CRW-trait control and VT Triple PRO treatments (Table 6 and Table 9). The similarity in WCR adult emergence between VT Triple PRO and the non-CRW-trait control indicates some level of Cry3Bb1 resistance in WCR in these fields (Table 6 and Table 9). In contrast, the significant reduction in mean WCR emergence from Herculex RW treatments compared to non-CRW-trait controls and VT Triple PRO (Table 6 and Table 9) indicates that WCR populations at those locations remained susceptible to Cry34Ab1/Cry35Ab1.

Mean WCR adult emergence was significantly reduced by MON87411, SmartStax and SmartStax PRO compared to the non-CRW-trait control and VT Triple PRO at all the moderate to high pressure locations (Tables 6-9) excepting Laneboro, MN in 2015. However, mean adult emergence from MON87411 was numerically higher than from Herculex RW at more than half of the locations with Herculex RW treatments (Table 6 and Table 9) and moderate to high WCR pressure. SmartStax PRO significantly reduced adult emergence at these same locations. In general, across years, locations, and levels of WCR pressure, mean adult emergence from SmartStax PRO was significantly lower than emergence from all other treatments with CRW traits, except SmartStax at eight locations (Tables 6-9). In fields where adult emergence from VT Triple PRO and the non-CRW-trait control treatments was similar and no difference was detected in adult WCR emergence between Herculex RW and SmartStax, it is likely that Cry3Bb1 resistance was more prevalent within the WCR population, that the contribution of Cry3Bb1 in MON87411 was minimal, and that DvSnf7 and Cry34Ab1/Cry35Ab1 were contributing more to the effectiveness of SmartStax PRO than Cry3Bb1. Under these challenging conditions, SmartStax PRO is likely to be more efficacious than other products.

\subsubsection{Northern corn rootworm emergence}

Across 14 locations in 2014 and 2015 where NCR were collected (Tables 6-9), adult NCR emergence was generally much lower than that of WCR. However, in 2014, emergence of NCR was similar to WCR at Breda, IA, Union Hill, $I L$, and Rudd, IA, and was greater than WCR emergence at Willey, IA, and Charles City, IA (Table 6 and Table 8). In general, mean adult NCR emergence per tent over the growing season in non-CRW-trait controls was less than 100 (considered very low) at five locations in 2014 (Union Hill, IL, Breda, IA, 
Newton, IA, Odgen, IA, and Willey, IA) and three locations in 2015 (Cumberland, IA, Mt. Auburn, IA, and Saunders, NE) (Tables 6-8). Mean NCR adult emergence from non-CRW-trait controls was greatest at Lanesboro, $M N$ ( 451 NCR) in 2014 (Table 8) and Washington, IA ( 443) in 2015 (Table 7) and considered moderate at these locations. Adult emergence was considered moderate to low for NCR at the remaining locations. At all locations, NCR emergence was numerically greatest in the non-CRW-trait control (Tables 6-9). Across location-years, pyramid CRW products almost always reduced adult NCR numbers significantly below the non-CRW-trait control (Tables 6-9).

Two single-trait treatments, VT Triple PRO and Herculex RW, were included at six NCR locations (the Monsanto locations in 2014 and the Dow AgroSciences locations in 2015; Table 6 and Table 9). However, only one of these locations (Lanesboro, MN) was considered to have moderate NCR adult emergence (Table 9). Abundance of NCR at the remaining five locations was low to extremely low, meaning that there was little variation in trait performance (Table 6 and Table 9). Overall, mean adult NCR emergence for VT Triple PRO at five of the six locations, and at four of the six locations for Herculex RW, was not significantly different from the non-CRW-trait control (Table 6 and Table 9). Statistically significant differences in adult NCR emergence between the non-CRW control and VT Triple PRO and Herculex RW were only observed at Willey, IA, in 2014 (Table 6) and between the nonCRW control and Herculex RW at Breda, IA, in 2014 (Table 6).

In general, treatments with more than one trait targeting CRW produced fewer NCR adults than the non-CRW-trait control. Adult emergence in MON87411 was significantly lower than in VT Triple PRO and the nonCRW-trait control at three of six locations and lower than Herculex RW at three of six locations (Table 6 and Table 9). At Ogden, IA, in 2014 (Table 6) and Lanesboro, MN, in 2015 (Table 9), emergence of NCR in SmartStax was not significantly different from the non-CRW-trait control. However, emergence from SmartStax was visibly much lower than from the non-CRW-trait control at Lanesboro and, at Ogden, all treatments, including the non-CRWtrait control, had extremely low NCR emergence ( $\leq 10$ beetles). SmartStax PRO significantly reduced NCR adult emergence relative to the non-CRWtrait control at five of six locations (Table 6 and Table 9). Only at Ogden in 2014 was no treatment effect observed between SmartStax PRO and the non-CRW-trait control (Table 6).

\subsection{Estimation of trait effects on WCR adult emergence}

The WCR emergence data pooled across years and locations with more than 100 beetles emerging from the non-CRW-trait control plots ( 11 locations 
in all) were used to estimate relative emergence on plants expressing individual proteins and various combinations of proteins by estimating select pairwise contrasts. Estimated relative emergence (referred to as trait effects) for individual traits, all pairs of traits, and the three-trait pyramid SmartStax PRO are presented in Table 10. In that table, the column "Ratio" presents estimated trait effects. For most traits, there was more than one estimate. For example, there were three estimates of the Cry34Ab1/Cry35Ab1 trait effect: one based on comparison of HXRW with non-CRW-trait control, one based on comparison of SmartStax PRO with MON 87411, and one based on comparison of SmartStax with VT3P. The corresponding estimates were $0.019,0.045$ and 0.028 (suggesting $98.1 \%, 95.5 \%$ and $97.2 \%$ control), which are similar to each other and to previous estimates of the impact of Cry34Ab1/Cry35Ab1.

There were two estimates of theDvSnf7 trait effect: one based on comparison of SmartStax PRO with SmartStax, which suggests that DvSnf7 reduced adult emergence by $87.7 \%$, and one based on the comparison of MON 87411 with VT3P, which suggests that DvSnf7 reduced adult beetle emergence by $92.5 \%$. In addition, comparison of MON 87411 emergence with the non-CRW-trait control at locations with apparent Cry3Bb1 resistance (Table 6) suggests that DvSnf7 control might vary between 80 and 95\%. Insect resistance models, described next, were evaluated assuming DvSnf7 control between $80 \%$ and $95 \%$.

Table 10. Trait effects (proportion surviving on that trait relative to negative control) estimated from combined analysis across 11 locations with more than 100 beetles emerging from control plots.

\begin{tabular}{|c|c|c|c|c|c|c|}
\hline Trait & Contrast & Log Ratio & $S E$ & Ratio & Lower 95\% CL & Upper 95\% CL \\
\hline DvSnf7 & $S S P-S S$ & -2.097 & 0.403 & 0.123 & 0.055 & 0.275 \\
\hline DvSnf7 & MON 87411 - VT3P & -2.593 & 0.503 & 0.075 & 0.027 & 0.205 \\
\hline Cry34Ab1/Cry35Ab1 & HXRW - Control & -3.946 & 0.457 & 0.019 & 0.008 & 0.048 \\
\hline Cry34Ab1/Cry35Ab1 & SSP - MON 87411 & -3.096 & 0.353 & 0.045 & 0.022 & 0.092 \\
\hline Cry34Ab1/Cry35Ab1 & SS - VT3P & -3.592 & 0.52 & 0.028 & 0.01 & 0.078 \\
\hline Cry3Bb1 & VT3P - Control & -0.096 & 0.497 & 0.908 & 0.336 & 2.457 \\
\hline Cry3Bb1 & SS - HXRW & 0.257 & 0.48 & 1.294 & 0.495 & 3.382 \\
\hline SS (Cry3Bb1+Cry34Ab1/Cry35Ab1) & SS - Control & -3.688 & 0.403 & 0.025 & 0.011 & 0.056 \\
\hline MON 87411 (DvSnf7+Cry3Bb1) & MON 87411 - Control & -2.689 & 0.353 & 0.068 & 0.034 & 0.138 \\
\hline MON 87411 (DvSnf7+Cry3Bb1) & SSP - HXRW & -1.84 & 0.457 & 0.159 & 0.064 & 0.397 \\
\hline DvSnf7+Cry34Ab1/Cry35Ab1 & SSP - VT3P & -5.689 & 0.497 & 0.003 & 0.001 & 0.009 \\
\hline SSP (DvSnf7+Cry3Bb1+Cry34Ab1/Cry35Ab1) & SSP - Control & -5.785 & 0.343 & 0.003 & 0.002 & 0.006 \\
\hline
\end{tabular}

"LogRatio" is the estimated pairwise difference on natural log scale, which is also the natural logarithm of the ratio of emergence. 


\subsection{Modeling the durability of SmartStax and SmartStax PRO to WCR resistance}

\subsection{Definition of product durability}

For SmartStax and SmartStax PRO, durability was defined as the time when resistance allele frequency reached 0.50 for both Cry3Bb1 and Cry34Ab1/ Cry35Ab1. DvSnf7 was excluded from this definition to provide a more appropriate comparison between SmartStax and SmartStax PRO, and because DvSnf7 alone will not be a commercial product.

\subsubsection{Model results}

Estimated durability of SmartStax and SmartStax PRO, based on assumptions in Table 3, are presented for a range of Cry3Bb1 and Cry34Ab1/Cry35Ab1 initial resistance allele frequencies and DvSnf7 fitness values (Fig. 4, with WRS/WSS assumed to be 2 for Cry34Ab1/Cry35Ab1, and Fig. 5, with WRS/ WSS assumed to be 7 for Cry34Ab1/Cry35Ab1). Assumed Cry3Bb1 resistance allele frequencies included levels that might represent "average" maize fields in the Corn Belt (0.05) and fields that contain WCR with increased levels of resistance (0.50) representing GTED-type grower fields. These GTED-type fields typically have a history of continuous exposure of CRW to Cry3Bb1 corn through repeated planting of the same product, an agronomic practice associated with higher resistance levels in WCR. ${ }^{6}$ Similarly, Cry34Ab1/ Cry35Ab1 resistance allele frequencies included levels assumed for "average" fields (0.01) and fields with signs of resistance (0.10). Several parameters were held fixed, as described in Table 3. Among them, the probability of larval movement will impact the absolute level of durability, with higher movement probability resulting in decreased durability. Although there is uncertainty about the extent of larval movement, the $50 \%$ larval movement assumed here (for one effective round of movement for SmartStax and two effective rounds of movement - or $75 \%$ overall probability of movement - for SmartStax PRO) is consistent with prior studies on larval movement.

Not surprisingly, durability is greater for SmartStax PRO than for SmartStax, with the advantage greater for lower values of WSS $_{\text {DvSnf }}$ and lower values of WRS/WSS for Cry3Bb1 and Cry34Ab1/Cry35Ab1. Across all scenarios, SmartStax PRO with a $5 \%$ seed blend refuge delayed resistance evolution 35-500\% longer than SmartStax with a 5\% seed blend refuge, amounting to a difference of about a year to more than 25 years in durability. With parameter values in the range expected for grower fields with lower resistance allele frequencies for Cry3Bb1 of 0.05 and 0.01 for Cry34Ab1/Cry35Ab1 and typically observed efficacy for DvSnf7 (90-95\% mortality) the durability of SmartStax PRO with a $5 \%$ seed blend refuge generally ranged from approximately two-fold greater to more than four-fold greater than for SmartStax with a $5 \%$ seed blend when WRS/WSS for Cry34Ab1/Cry35Ab1 is assumed 

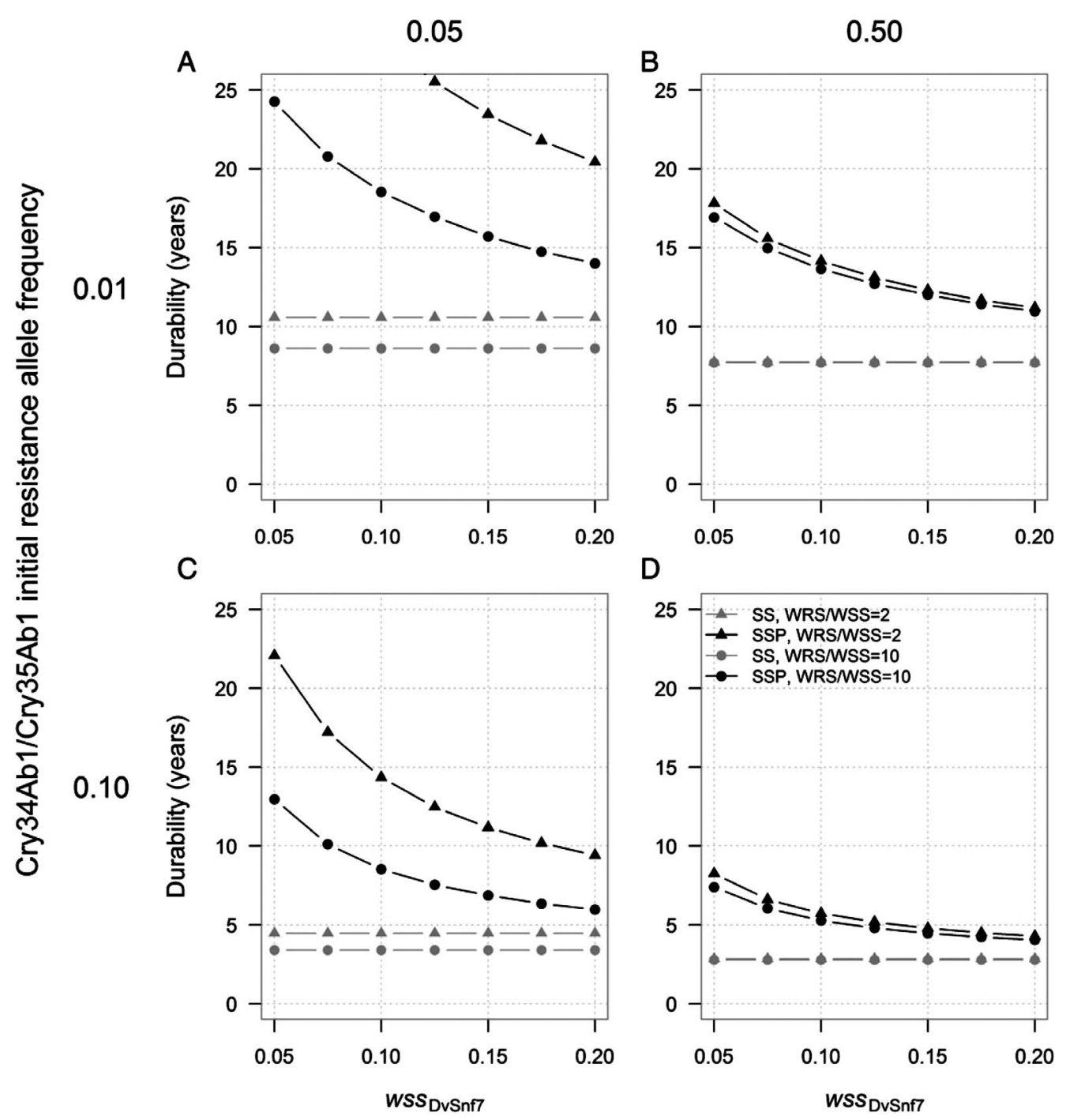

D

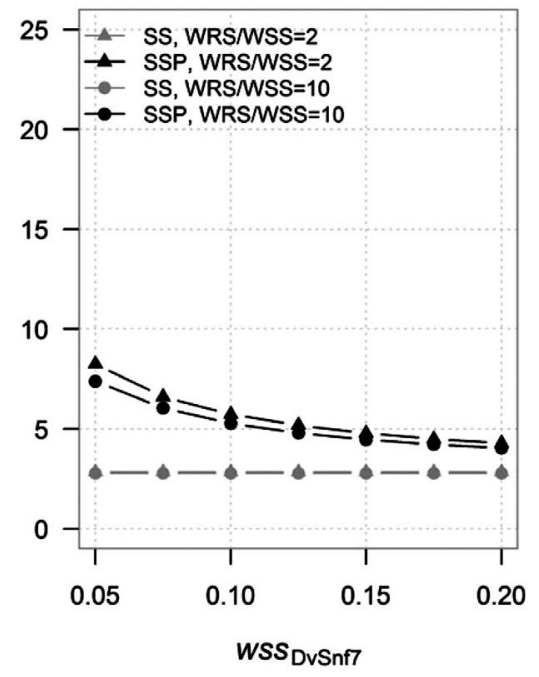

Figure 4. Durability of Cry3Bb1+Cry34Ab1/Cry35Ab1 in SmartStax (gray lines) and SmartStax PRO (black lines), for two different levels of Cry3Bb1 WRS/WSS fitness, and Cry34Ab1/Cry35Ab1 and DvSnf7 WRS/WSS held fixed at 2. Each of the four panels (labeled A-D) shows durability of Cry3Bb1+Cry34Ab1/Cry35Ab1 in years $(y$ axis) as a function of fitness of susceptible WCR larvae to DvSnf7 ( $x$-axis) for a different combination of initial resistance allele frequencies for Cry3Bb1 and Cry34Ab1/ Cry35Ab1. Other model parameters are given in Table 3.

to be two (Fig. 4). In cases where WRS/WSS for Cry34Ab1/35Ab1 is assumed to be higher at seven (Fig. 5), the durability of SmartStax PRO with a 5\% seed blend was slightly improved due to the contribution of DvSnf7 ranging from over two-fold greater to four-fold greater compared to SmartStax with a 5\% refuge. In fields assumed to have CRW with increased levels of resistance to either Cry3Bb1 or Cry34Ab1/Cry35Ab1 but not both (Fig. 4B and C, Fig. 


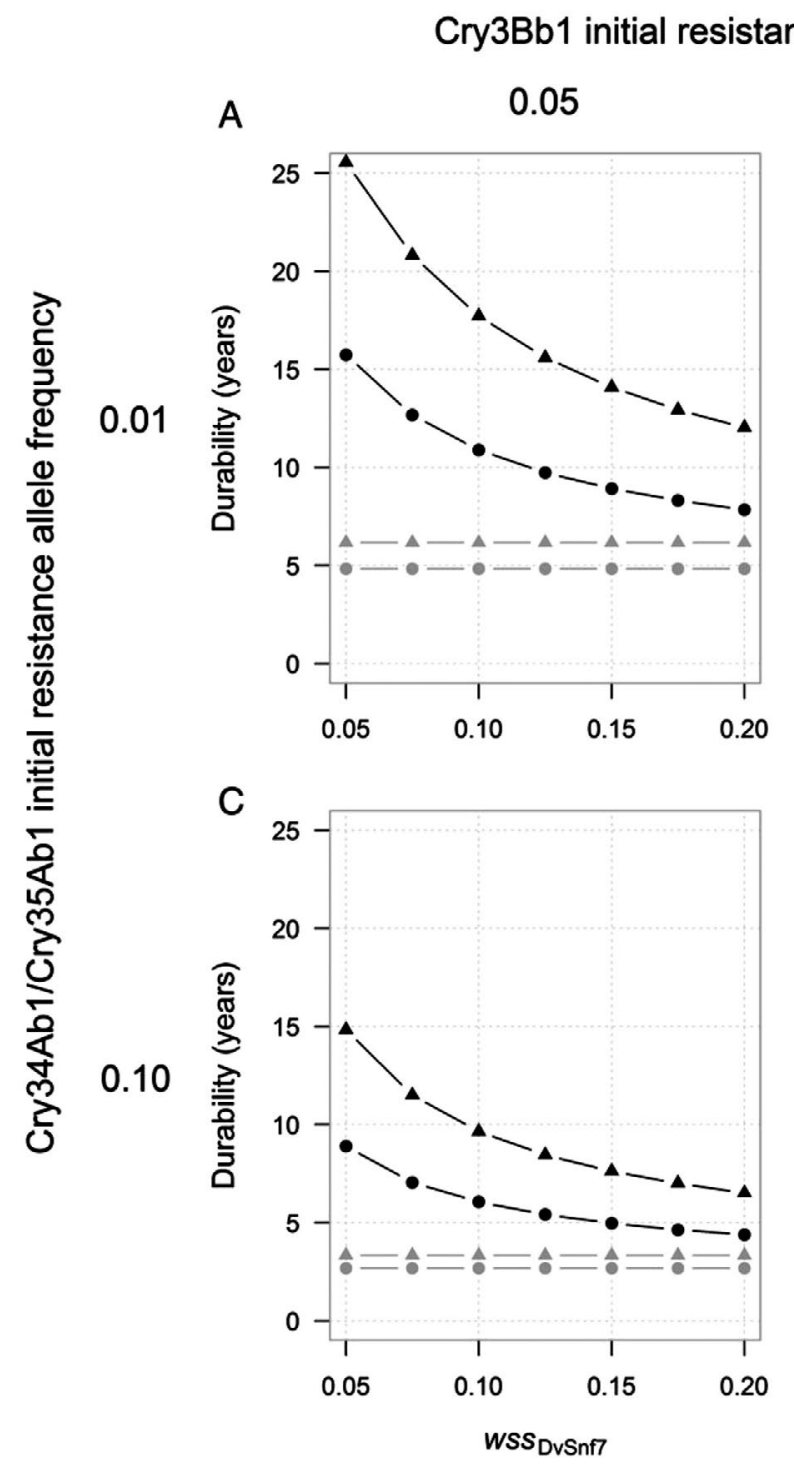

B $\quad 0.50$
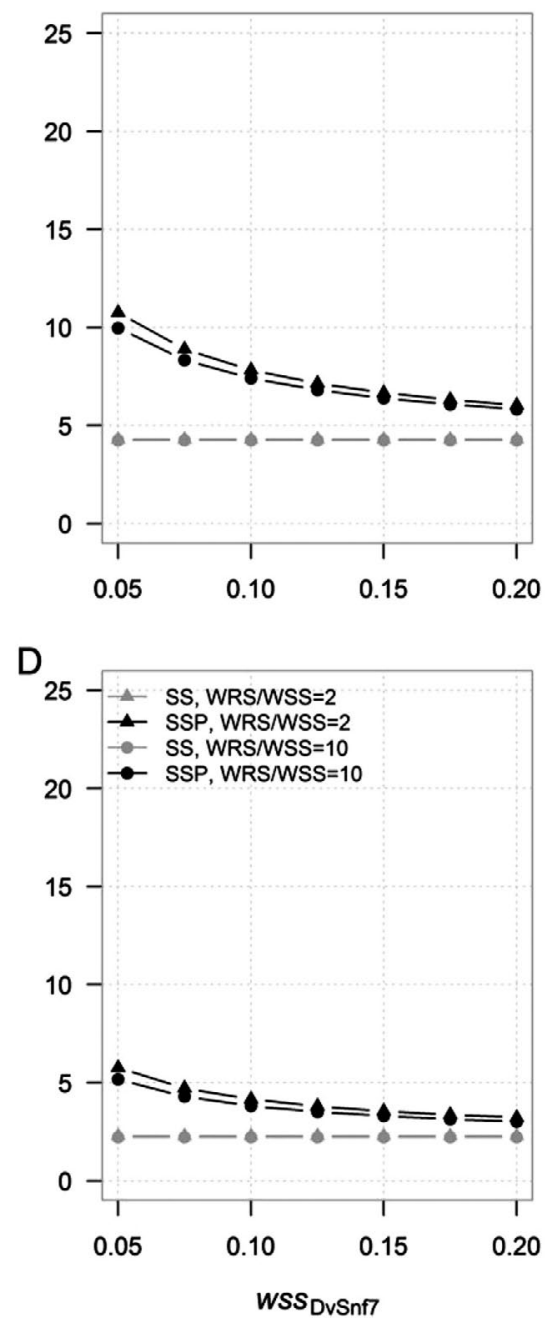

Figure 5. Durability of Cry3Bb1+Cry34Ab1/Cry35Ab1 in SmartStax (gray lines) and SmartStax PRO (black lines), for two different levels of Cry3Bb1 WRS/WSS fitness, Cry34Aba/Cry35Ab1 four panels (labeled A-D) shows durability of Cry3Bb1 + Cry34Ab1/Cry35Ab1 in years ( $y$-axis) as a function of fitness of susceptible WCR larvae to DvSnf7 ( $x$-axis) for a different combination of initial resistance allele frequencies for Cry3Bb1 and Cry34Ab1/Cry35Ab1. Other model parameters are given in Table 3.

5B and C), DvSnf7 still contributed to improved durability of SmartStax PRO compared to SmartStax. The durability advantage of SmartStax PRO is lowest in cases where resistance to both Cry3Bb1 and Cry34Ab1/Cry35Ab1 is already present (Fig. 4D and Fig. 5D). 


\section{Discussion}

Similar to earlier results obtained by Prasifka et al. ${ }^{3}$ and Head et al. ${ }^{4}$ for SmartStax, the results here show that the pyramid products SmartStax and SmartStax PRO can provide protection from larval feeding and are both capable of significantly reducing adult CRW emergence over a range of relevant conditions. As resistance evolves to single- $B t$ traits that have been deployed for nearly a decade, ${ }^{6,7,26,27}$ the durability of pyramid products containing these $B t$ traits is reduced, emphasizing the need for novel modes of action against CRW. Here we provide evidence that on grower fields where WCR densities are high and resistance to Cry3Bb1may be present, the addition of DvSnf7 in SmartStax PRO can reduce root damage compared to SmartStax and prolong the durability of Cry3Bb1 and Cry34Ab1/Cry35Ab1.

\subsection{SmartStax and SmartStax PRO provide protection in fields with suspected $\mathrm{Cry} 3 \mathrm{Bb} 1$ resistance}

Pyramiding multiple genes in combination with refuge is considered the most effective way to manage resistance. ${ }^{28}$ For pyramids targeting CRW, the presence of resistance to some of the components will limit product durability ${ }^{29}$ but these products still are more durable than single $B t$ products. In fact, the data presented here show that, over 3 years and many locations, the pyramid products SmartStax and SmartStax PRO consistently protected maize plants and reduced root injury to below 0.5 NIS at nearly all locations. In addition, we examined two primary drivers of differential trait performance that are likely to contribute to significant CRW larval feeding on maize hybrids with traits targeting WCR or NCR: population density $21,30,31$ and degree of resistance to Cry3Bb1 within the population. At locations with little or no CRW pressure, large differences in trait performance are not expected. However, the relative advantage of SmartStax PRO over SmartStax correlated with increasing insect pressure and indicated that DvSnf7 contributed significantly to root protection under heavier CRW pressure or where Bt resistance may be present. SmartStax PRO also reduced adult emergence more consistently than SmartStax over a range of WCR densities at sites where Cry3Bb1 resistance was presumed present. These results demonstrate the value of SmartStax PRO as a management tool for WCR. Under conditions where resistance to one of the component traits may be present, SmartStax PRO with an additional mode of action should be more durable than SmartStax. Furthermore, DvSnf7 provides additional control of NCR and, when combined with Cry3Bb1 and Cry34Ab1/Cry35Ab1, consistently reduced adult NCR emergence compared to the non-CRW-trait control, making SmartStax PRO a suitable product for northern Corn Belt areas where NCR is prevalent. 


\subsection{SmartStax PRO provides improved durability compared to SmartStax}

In the modeling analysis, SmartStax PRO durability was greater than that of SmartStax across a range of scenarios, including scenarios in which initial resistance allele frequencies were high for all $B t$ proteins. With parameter values in the range expected for most grower fields (resistance allele frequencies for Cry3Bb1 of 0.05 and 0.01 for Cry34Ab1/Cry35Ab1), and assumed $90 \%$ mortality due to DvSnf7, the durability of SmartStax PRO was at least two-fold greater than for SmartStax. Under conditions where WCR have increased levels of resistance to either Cry3Bb1 or Cry34Ab1/Cry35Ab1, the durability advantage of SmartStax PRO with DvSnf7 versus SmartStax is greater precisely because the durability of current CRW traited-technologies is limited under these conditions.

\subsection{Value of product testing on fields with greater-than-expected damage from WCR}

The results reported here demonstrate the advantage of evaluating products under conditions of high pressure and differing degrees of resistance. Intentionally targeting product testing efforts to WCR and NCR populations that are relevant to grower experience is a necessary strategy that enables the rigorous assessment of product performance, which is not always readily predicted from artificially infested fields or greenhouse trials. The demonstrated efficacy of SmartStax and SmartStax PRO under these conditions reinforces the suitability of pyramid products as management tools ${ }^{4}$ for WCR or NCR problem fields even under conditions where Cry3Bb1 resistance may be prevalent in the WCR population. Furthermore, testing on GTED fields can help generate performance data that inform how to improve product stewardship in an environment with a small number of CRW traits, WCR resistance to Cry3Bb1 and Cry34Ab1/Cry35Ab1, and cross-resistance between Cry3Bb1 and traits in other products. Improved knowledge of product performance helps in educating growers and managing expectations. As grower confidence in the ability of a product to maintain yield across a range of WCR or NCR pressure improves, prophylactic use of soil- and seed-applied insecticides for CRW management should decline.

\section{Conclusions}

Both SmartStax and SmartStax PRO reduced WCR and NCR larval feeding injury and adult emergence in field studies with high CRW pressure. However, on fields where the performance of the single-Bt product, VT Triple 
PRO, suggested that resistance to Cry3Bb1 was prevalent in the WCR population, SmartStax PRO was usually more efficacious and reduced adult emergence compared to SmartStax. Furthermore, resistance evolved more slowly to SmartStax PRO than SmartStax in all resistance modeling scenarios, indicating that SmartStax PRO can prolong the durability of Cry3Bb1 and Cry34Ab1/Cry35Ab1 relative to SmartStax even with elevated resistance allele frequencies to either or both Cry3Bb1 and Cry34Ab1/Cry35Ab1.

Together, the data presented here show that 1) the criteria used for selecting fields were successful in identifying locations where CRW population pressure was high and resistance to Cry3Bb1 likely was present; 2) the pyramids SmartStax and SmartStax PRO both provided root protection and effectively managed WCR and NCR across a range of conditions that included high WCR pressure and presumed resistance to Cry3Bb1; and 3) SmartStax PRO was usually more effective against high WCR population densities than SmartStax and should provide improved IRM value over SmartStax in fields where CRW densities are high and resistance to either Cry3Bb1 or Cry34Ab1/ Cry35Ab1 may be prevalent.

Acknowledgments - The authors thank members of Dow AgroSciences and Monsanto who contributed time, data and technical assistance to studies contained in this manuscript. The authors acknowledge the assistance of Virginia M. Peschke of Oakside Editorial Services in the preparation of the manuscript.

\section{References}

1 Moellenbeck D, Peters ML, Bing JW, Rouse JR, Higgins L, Sims L et al., Insecticidal proteins from Bacillus thuringiensis protect corn from corn rootworms. Nat Biotechnol 19:668-672 (2001).

2 Vaughn T, Cavato T, Brar G, Coombe T, DeGooyer T, Ford S et al., A method of controlling corn rootworm feeding using a Bacillus thuringiensis protein expressed in transgenic maize. Crop Sci 45:931-938 (2005).

3 Prasifka PL, Rule DM, Storer NP, Nolting SP, and Hendrix III WH, Evaluation of corn hybrids expressing Cry34Ab1/Cry35Ab1 and Cry3Bb1 against the western corn rootworm (Coleoptera: Chrysomelidae). J Econ Entomol 106:823-829 (2013).

4 Head G, Carroll MW, Clark TL, Galvan T, Huckaba RM, Price P et al., Efficacy of SmartStax insect-protected corn hybrids against corn rootworm: The value of pyramiding the Cry3Bb1 and Cry34/35Ab1 proteins. Crop Prot 57:38-47 (2014).

5 Gould F, Sustainability of transgenic insecticidal cultivars: Integrating pest genetics and ecology. Annu Rev Entomol 43:701-726 (1998).

6 Gassmann AJ, Petzold-Maxwell JL, Keweshan RS, and Dunbar MW, Field-evolved resistance to $B t$ maize by western corn rootworm. PLoS One 6:e22629 (2011). 
7 Gassmann AJ, Petzold-Maxwell JL, Clifton EH, Dunbar MW, Hoffmann AM, Ingber DA et al., Field-evolved resistance by western corn rootworm to multiple Bacillus thuringiensis toxins in transgenic maize. Proc Natl Acad Sci U S A 111:5141-5146 (2014).

8 Jakka SRK, Shrestha RB and Gassmann AJ, Broad-spectrum resistance to Bacillus thuringiensis toxins by western corn rootworm (Diabrotica virgifera virgifera). Sci Rep 6:27860 (2016).

9 Gassmann AJ, Shrestha RB, Jakka SRK, Dunbar MW, Clifton EH, Paolino AR et al., Evidence of resistance to Cry34/35Ab1 corn by western corn rootworm (Coleoptera: Chrysomelidae): Root injury in the field and larval survival in plant-based bioassays. J Econ Entomol 109:1872-1880 (2016).

10 Bolognesi R, Ramaseshadri P, Anderson J, Bachman P, Clinton W, Flannagan R et al., Characterizing the mechanism of action of double-stranded RNA activity against western corn rootworm (Diabrotica virgifera virgifera LeConte). PLoS One 7:e47534 (2012).

11 Koči J, Ramaseshadri P, Bolognesi R, Segers G, Flannagan R, and Park Y, Ultrastructural changes caused by Snf7 RNAi in larval enterocytes of western corn rootworm (Diabrotica virgifera virgifera Le Conte). PLoS One 9:e83985 (2014).

12 Metcalf RL, Foreword, in Methods for the Study of Pest Diabrotica, ed. by Krysan $J L$ and Miller TA. Springer-Verlag, New York, pp. vii-xv (1986).

13 Mitchell PD, Gray ME, and Steffey KL, A composed-error model for estimating pest-damage functions and the impact of the western corn rootworm soybean variant in Illinois. Am J Agric Econ 86:332-344 (2004).

14 Sappington TW, Siegfried BD, and Guillemaud T, Coordinated Diabrotica genetics research: accelerating progress on an urgent insect pest problem. Am Entomol 52:90-97 (2006).

15 Wangila DS, Gassmann AJ, Petzold-Maxwell JL, French BW, and Meinke LJ, Susceptibility of Nebraska western corn rootworm (Coleoptera: Chrysomelidae) populations to Bt corn events. J Econ Entomol 108:752-760 (2015).

16 Moar W, Khajuria C, Pleau M, llagan O, Chen M, Jiang C et al., Cry3Bb1resistant western corn rootworm, Diabrotica virgifera virgifera (LeConte) does not exhibit cross-resistance to DvSnf7 dsRNA. PLoS One 12:1-15 (2017).

17 Oleson JD, Park YL, Nowatzki TM and Tollefson JJ, Node-injury scale to evaluate root injury by corn rootworms (Coleoptera: Chrysomelidae). J Econ Entomol 98:1-8 (2005).

18 R Development Core Team, R: A Language and Environment for Statistical Computing. [Online]. R Foundation for Statistical Computing, Vienna (2014). http://www.r-project.org [20 June 2016]

19 Hommel G, A stagewise rejective multiple comparison procedure based on a modified Bonferroni test. Biometrika 75:383-386 (1988).

20 Head G, Campbell LA, Carroll M, Clark T, Galvan T, Hendrix WM et al., Movement and survival of corn rootworm in seed mixtures of SmartStax insectprotected corn. Crop Prot 58:14-24 (2014). 
21 Hibbard BE, Higdon ML, Duran DP, Schweikert YM and Ellersieck MR, Role of egg density on establishment and plant-to-plant movement by western corn rootworm larvae (Coleoptera: Chrysomelidae). J Econ Entomol 97:871-882 (2004).

22 Meihls LN, Higdon ML, Siegfried BD, Miller NJ, Sappington TW, Ellersieck MR et al., Increased survival of western corn rootworm on transgenic corn within three generations of on-plant greenhouse selection. Proc Natl Acad Sci U S A 105:19177-19182 (2008).

23 Ingber DA and Gassmann AJ, Inheritance and fitness costs of resistance to Cry3Bb1 corn by western corn rootworm (Coleoptera: Chrysomelidae). J Econ Entomol 108:2421-2432 (2015).

24 Storer NP, Babcock J and Jeffrey M, Field measures of western corn rootworm (Coleoptera: Chrysomelidae) mortality caused by Cry34/35Ab1 proteins expressed in maize event 59122 and implications for trait durability. J Econ Entomol 99:1381-1387 (2006).

25 Wright R, Meinke LJ and Jarvi KJ, Corn Rootworm Management. [Online]. Nebraska Cooperative Extension EC99-1563, pp. 1-13 (1999). http:// digitalcommons.unl.edu/extensionhist/1084 [29 November 2016].

26 Gassmann AJ, Field-evolved resistance to Bt maize by western corn rootworm: Predictions from the laboratory and effects in the field. J Invertebr Pathol 110:287-293 (2012).

27 Frank DL, Zukoff A, Barry J, Higdon ML, and Hibbard BE, Development of resistance to eCry3.1Ab-expressing transgenic maize in a laboratory-selected population of western corn rootworm (Coleoptera: Chrysomelidae). J Econ Entomol 106:2506-2513 (2013).

28 Roush RT, Two-toxin strategies for management of insecticidal transgenic crops: Can pyramiding succeed where pesticide mixtures have not? Phil Trans $R$ Soc Lond B 353:1777-1786 (1998).

29 Carriere Y, Fabrick JA, and Tabashnik BE, Can pyramids and seed mixtures delay resistance to Bt crops? Trends Biotechnol 34:291-302 (2016).

30 Branson TF, Sutter GR, and Fisher JR, Plant response to stress induced by artificial infestations of western corn rootworm. Environ Entomol 9:253-257 (1980).

31 Hibbard BE, Meihls LN, Ellersieck MR, and Onstad DW, Density-dependent and density-independent mortality of the western corn rootworm: Impact on dose calculations of rootworm-resistant Bt corn. J Econ Entomol 103:77-84 (2010). 